7-Ag8:3:36l V. S. Department of Agriculture

Bulletin 361

Tifice of Experiment Stations

$$
\text { Tibrary. }
$$

\title{
CROSSED SWEET CORN
}

Donald F. Jones and W. Ralph Singleton

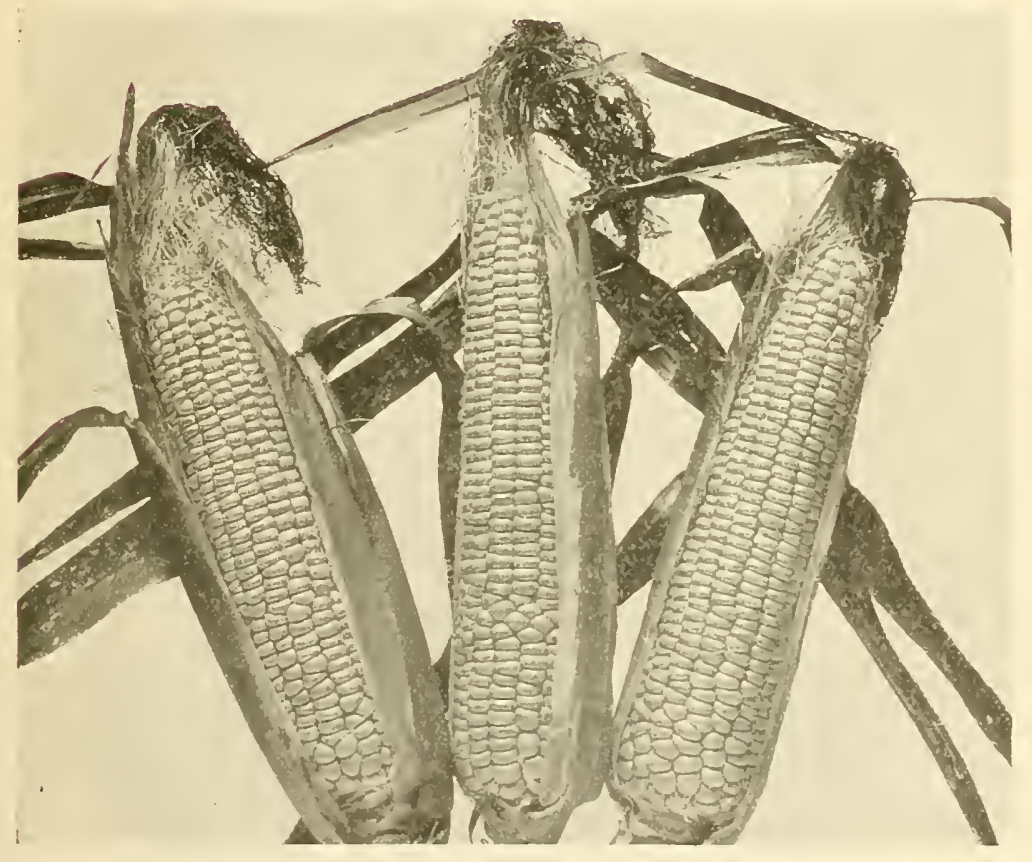

\section{Conmertirnt}

\section{Anrintltural Extariment Statinut}

ลัru 


\section{CONNECTICUT AGRICULTURAL EXPERIMENT STATION}

\section{BOARD OF CONTROL}

His Excellency, Governor Wilbur 1. Cross, ex-officio, President

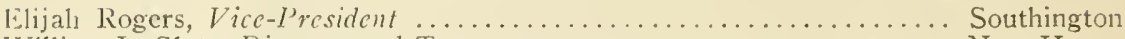
William L. Slate, Director and Treasurer .................... New Haven Edward C. Schneider, Secretary ........................ Middletown

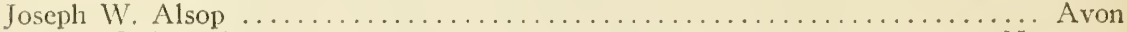
Charles G. Morris ................................. Newtown

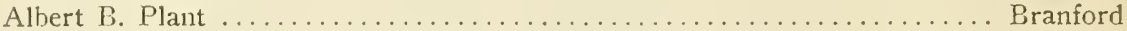

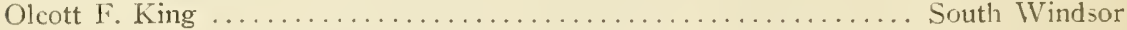

\section{STAFF}

Administration.

Analytical

Chemistry.

Biochemistry.

Botany.

Entomology.

Forestry.

Plant Breeding.

Soils.

Tobacco Substation at Windsor.
William L. Slate, B.Sc., Director and Treasurer.

Miss L. M. Brautiecht, Bookkerper and Librarian.

Miss Katirerine M. Patumer, B.J.tit., Editor.

G. E. GRAHAM, In Charge of Buildings and Grounds.

E. M. Bailey, Ph.D., Chemist in Charge.

C. E. Shepard

OWEN L. NOLAN

Harry J. Fisher, Pit.D. Assistant Chemists.

W. T. Mathis

David C. WALDEN, B.S.

Frank C. SHeldon, Laboratory Assistont.

V. L. ChurchilL, Sampling Agent.

Mrs. A. B. Vosburgh, Secretary.

H. B. Vickery, Рн.D., Biochemist in Charge.

Lafayette B. Mendei, Ph.D. Research Associate (Yale University). George W. Pucher, Pr.D., Assistant Biochemist.

G. P. ChInton, Sc.D., Botanist in Charge.

E. M. Stoddard, B.S., Pomologist.

Miss Florence A. MCCörMick, Ph.D., Pathologist.

A. A. Dunlap, Ph.D., Assistant Mycologist.

A. D. McDonnels, General Assistant.

Mrs. W. W. Kelsey, Secretary.

IV. E. Britton, Ph.D., D.Sc., Entomologist in Charge, State Entomologist.

B. H. WALDEN, B.AGR.

M. P. ZAPPE, B.S.

Philip Garman, PH.D. $\}$ Assistant Entomologists.

Roger B. Friend, Ph.D.

Neely Turner, M A.

ToHn T. Ashworth, Deputy in Charge of Gipsy Moth Control.

R. C. Botsford, Deputy in Charge of Mosquito Elimination.

T. P. JoHnson, B.S., Deputy in Charge of Japanese Beetle Quarantine.

Miss Helen A. Hulse $\}$ Secretarics.

Walter O. Filley, Forester in Charge.

H. W. Нrсоск, M.F., Assistant Forester.

J. E. Riley, JR., M.F., In Charge of Blister Rust.Control.

Miss Pauline A. Merchant, Sccretary.

Donald F. Jones, Sc.D., Geneticist in Charge.

W. Ralph Singleton, Sc.D., Assistant Geneticist.

LaWrence C. Curtis, B.S., Assistant.

Miss Genevieve Boоth, A.B., Secretary.

M. F. Morgan, M.S., Agronomist in Charge.

H. G. M. JA COBSON, M.S., Assistant Agronomist.

Herbert A. Lunt, Ph.D., Assistant in Forest Soils.

Dwight B. Downs, General Assistant.

Paul J. Anderson, Ph.D., Pathologist in Charge.

T. R. SWANBACK, M.S.. Agronomist.

O. E. Street, Ph.D. Plant Physiologist.

Miss Dorothy Lenard, Secretary. 


\section{CONTENTS}

PAGE

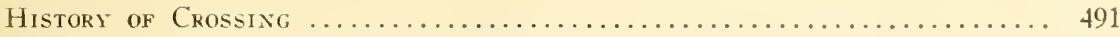

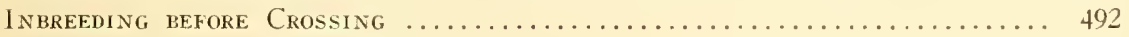

Selection in Self-Fertilized Lives .......................... 492

Maximula Hybrid Vigor in the First Generation .................... 492

Uniformiti of Crosses of Inbren Strains ....................... 493

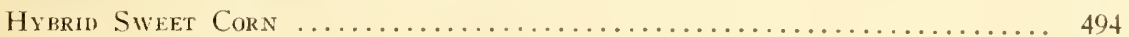

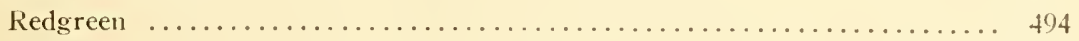

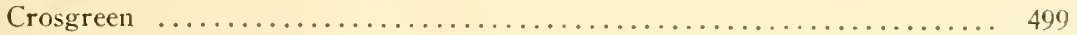

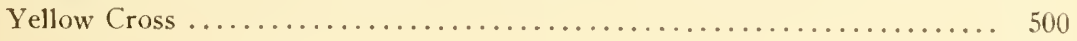

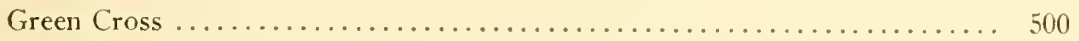

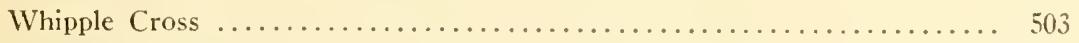

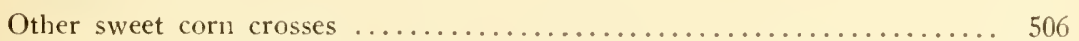

The Production of Inbred Strains ........................... 510

The Technique of Hand-Poldination . . . . . . . . . . . . . . . 512

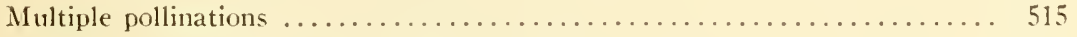

Production of Crossed Seen in Fiel.i Plots ..................... 516

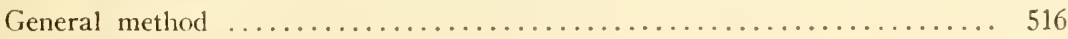

Number of rows of seed parent and pollen parent ............. 516

Yield of inbreds .......................................... 517

Time of planting .............................................. 517

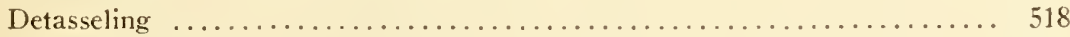

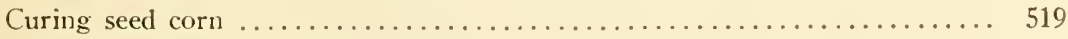

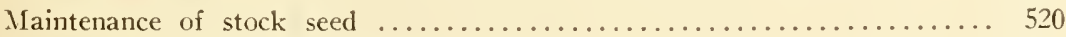

Increase from original hand-pollinated seed $\ldots \ldots \ldots \ldots \ldots \ldots \ldots \ldots . \ldots 20$

Isolated fields ..................................... 520

Hand-pollination of foundation stock ...................... 521

Rogueing ........................................ 521

Use of pollen parent seed from crossing field ................... 522

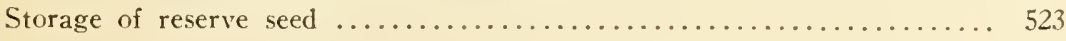




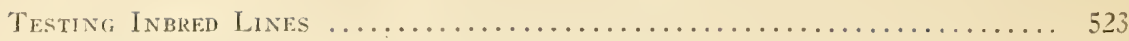

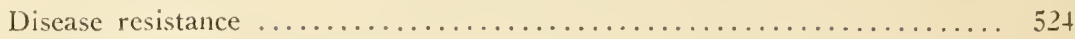

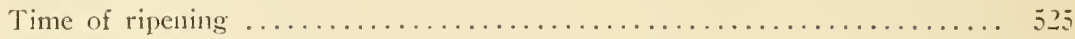

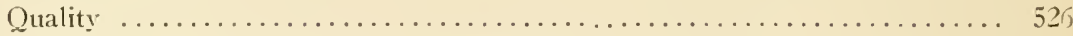

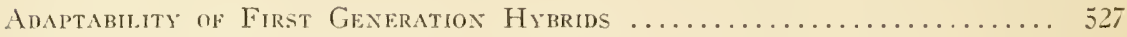

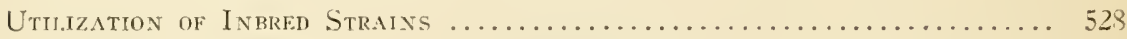

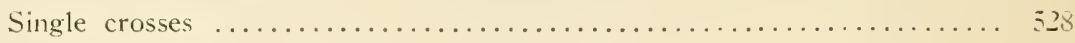

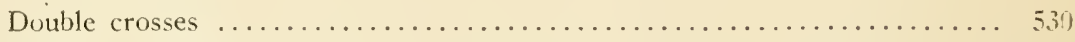

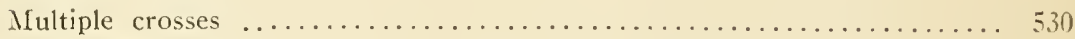

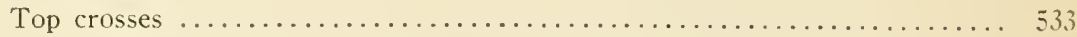

Crosses of Different Types compared with Crosses Within Variztis ... 535

Ability of Crosses to repent their Performance .................. 536 


\title{
CROSSED SWEET CORN
}

\author{
Donald F. Jones and W. Ralph Singleton
}

Vigorous healthy plants, well-filled ears on every stalk, ears even in size and shape and ripening at the same time; these are some of the reasons why crossed sweet corn seed is being used more and more each year. The first cross-bred seed of field corn produced by inbred plants was grown in 1920. The first commercial seed field of the same kind was grown by George S. Carter in 1921 at Clinton, Connecticut. By 1930, the use of cross-bred seed corn had increased to 34,000 acres. In 1931 it was estimated that 64,000 acres were grown and 111932 there were more than 80,000 acres planted to crosses including both field and sweet corn.

\section{History of Crossing}

More than fifty years ago, William J. Beal of the Michigan Agricultural College proposed a method for crossing field corn seed by planting two different varieties in the same field in alternating rows and pulling out all the tassels of one variety before pollen was shed. It was found that such crossed seed had a considerable advantage from hybrid vigor. The increased growth resulting from crossing somewhat unrelated types had long been noted and used in animal breeding. Mules, the sterile hybrid of the horse and ass, crossbred swine, sheep and cattle had. a recognized place in animal production.

$\mathrm{U}_{\mathrm{p}}$ to recent times the use of plant hybrids has been restricted to vegetatively propagated species. Nearly all cultivated varieties of orchard and bush fruits owe their superiority in some measure to vigor derived from crossing somewhat unrelated forms. The hybrid condition is maintained from generation to generation by budding, grafting or other forms of vegetative reproduction. Potatoes, sweet potatoes, sugar cane, also perpetuate a hybrid condition by vegetative propagation. The luxurious growth of many ornamental trees and bushes is associated with their hybrid nature.

Although it has been known that crossing often benefits seed-propagated plants, little was done to utilize this advantage largely because of the difficulty and expense of producing crossed seed. Corn is so constituted that it can be cross-fertilized easily. But it has been so continually interpollinated naturally that the cross breeding of similar varieties has not given enough advantage to bring about the use of varietal crosses. 


\section{Inbreeding Before Crossing}

Early in the prescnt century it was discovered that a process of close inbrecding applied for several generations before crossing produced a remarkable result in increased production and an even more striking effect in uniformity. This uniformity had no particular advantage in field corn, other than its effect on yield, but it was realized that it was especially desirable in sweet corn for the market and for canning.

\section{Selection in Self-Fertilized Lines}

At first the advantage from crossing was thought to be derived from the stimulus to increased growth, rapid maturity and greater hardiness, manifestations that were summed up in the term hybrid vigor. Nearly every cross of inbred strains gave such an astonishing increase in yield when compared with its inbred parents that it did not seem to make much difference what was used to make the cross. When these crosses were compared critically, with the original variety and against other varieties, it was soon realized that much depended on the inbred strains themselves. Crosses made with inbred strains were so uniform that if they had any defects these became most apparent when every plant had the undesirable feature. Many crosses did well one year and in one place, but failed in adaptability to other locations and to other seasons.

For all of these reasons attention was soon directed to the production of the inbred strains themselves. This subject is being presented in a series of bulletins under the general title of "The Improvement of Naturally Cross-Pollinated Plants by Selection in Self-Fertilized Lines". The first of this series has been published as Bulletin 266 of the Connecticut Agricultural Experiment Station under the title of "The Production of Inbred Strains of Corn". The results may be summarized briefly. Selection is only partially effective in isolating desirable characters during the process of reduction to uniformity and constancy. During the early generations of inbreeding much defective heredity is brought into visible expression and eliminated by natural selection. After this process is completed then selection is most effective in discovering the best material to work with. It is important to have as many inbred lines as possible in order to find those qualities that are desired. In the inbred condition they are sometimes hard to recognize. This usually means that many different combinations must be made and tested under different soil and seasonal conditions. Various ways of making these tests and comparisons are now being tried out. The results will be brought together as the second publication of the series.

This bulletin is designed to bring together in a brief form as much of this information as is already available. Many of the statements made here are supported by experimental evidence that will be published later.

\section{Maximum Hybrid Vigor in First Generation}

Having once obtained a valuable combination it is necessary to make the cross each year to gain the full value of this method of producing 
seed. The plants grown from the cross-fertilized seed are usually referred to as the first generation hybrid or the $F_{1}$, (first filial generation) to distinguish them from later generations.

The uniformity, vigor and productiveness resulting from the crossing of inbred strains is shown only the first year. The second generation falls off in yield from 15 to 20 per cent and loses much of the uniformity that is so noticeable in the first generation. This inability of a seed-propagated plant to reproduce itself is a new feature in plant culture, one that growers are not familiar with, and at first they are not willing to accept the facts. The falling off in yield has been well established in repeated tests. It is shown by all hybrids although some will show more of a reduction than others. It is unavoidable and results from the mechanism of heredity that is fundamentally the same for all plants and animals. Animal breelers know that cross-bred pigs, sheep and cattle, after the first cross, are not worth growing for the market. Crossbred poultry are sometimes carelessly allowed to reproduce into later generations with the production of bizarre forms that most poultrymen would be ashamed to have around the farm.

Corn growers have not had enough experience with cross-bred seed to realize their loss in saving seed from the splendid plants of the first cross. In some cases the second generation is enough better than ordinary varieties to justify its use where the first generation seed can not be obtained. Most growers who have used second generation secd have made no critical comparison and do not realize the loss ther are taking in the form of reduced rield and increased variability.

\section{Uniformity of Crosses of Inbred Strains}

The uniformity of crosses in which inbred strains are used is apparent in all parts of the plant. It is most noticeable in the erenness in lieight. in the size and shape of the tassels and in time of tasseling and silling. This similarity continues to the time of ripening. If the corn is grown on soil of the same texture and fertility nearly all of the ears can be harvested at one time. This enables the market gardener to clean up a field in a short time and have it ready for another crop. It is particularly important for the canner. Ustrally only one picking is made. In the past, many ears were left in the field because they were not ready to gather and many ears that were harvested were too green or too ripe to make the best grade of canned product. With this evemness in maturity there is also a marked similarity in size and shape of ear, as well as in color and formation of the kernels. This uniformity in shape is important in corn that is being cut for the whole-grain pack.

Although uniformity is desirable in many ways it does have certain disadvantages in coril. This plant is so constructed that there is a critical stage in its development when pollination takes place. The tassels and silks are so exposed that severe heat, low humidity and lack of moisture in the soil may seriously reduce the set of seed. Adverse conditions at any stage may stunt the plants and reduce the size and development of the ear. Crossed plants being all alike are usually in the same stage of development and may be affected in the same way. This applies 
particularly to crosses between two inbred strains. Other kinds of crosses permit more variation and under some conditions this is desirable. This sensitiveness to adverse weather conditions is also shown in the behavior of crosses grown on different soils. Certain hybrid combinations that have done remarkably well one year in one locality have given poor results when grown another year in the same place.or in different places the same year. This has been overcome by finding strains that are sufficiently hardy and adaptable to give good results nearly every year and in almost all localities where reasonably good growing conditions prevail. Such strains have great value but are not easily obtained. Crosses must

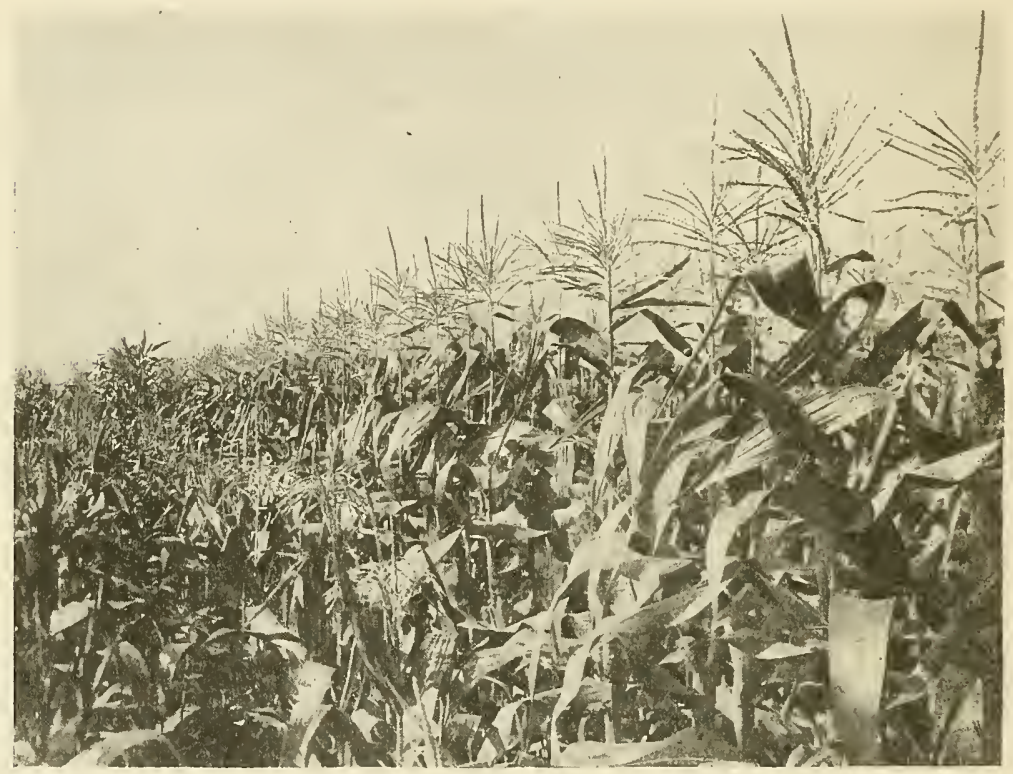

FIGCRE 86. A first generation cross of two inbred strains showing evenness in height and tassel formation.

be tested over a wide range of soil and seasonal conditions before they can be generally recommended, and few crosses will do well over any large territory. This means that seed corn production will always be a local problem. Each locality should be able to produce better types of corn for its own conditions than can be produced from afar. Until locally adapted types are developed, some of the hybrid combinations that are available may do better than any local variety, but this should always be established by test.

\section{Hybrid Sweet Corn \\ Redgreen}

One of the first cross-bred sweet corns to be widely grown is Redgreen (Red-leaved white-seeded Evergreen), a product of the Connecticut Agricultural Experiment Station, first distributed for trial in 1924. It 
is a cross of an inbred strain of Stowell's Evergreen No. 77 as a pollen parent on inbred No. 75, a small-seeded, sweet corn with reddish plant color. This color is developed only in sunlight. The record of the origin of this inbred No. 75 has been lost. The original seed resulted from the study of aleurone color reported in bulletin 167 on "Inheritance in Maize". It probably had a mixed origin. The plant color and texture of the seed is quite similar to a local variety of corn called Farmers' Club. The shape of ear is considerably different.

The original seed was self-fertilized for several generations and used as an aleurone tester, having the composition $A C r p r$. It was used in a number of crosses in a study of inheritance. The well-developed ears that resulted from these crosses were noted for several years. Various crosses with other sweet corn strains were tried on the table. When crossed

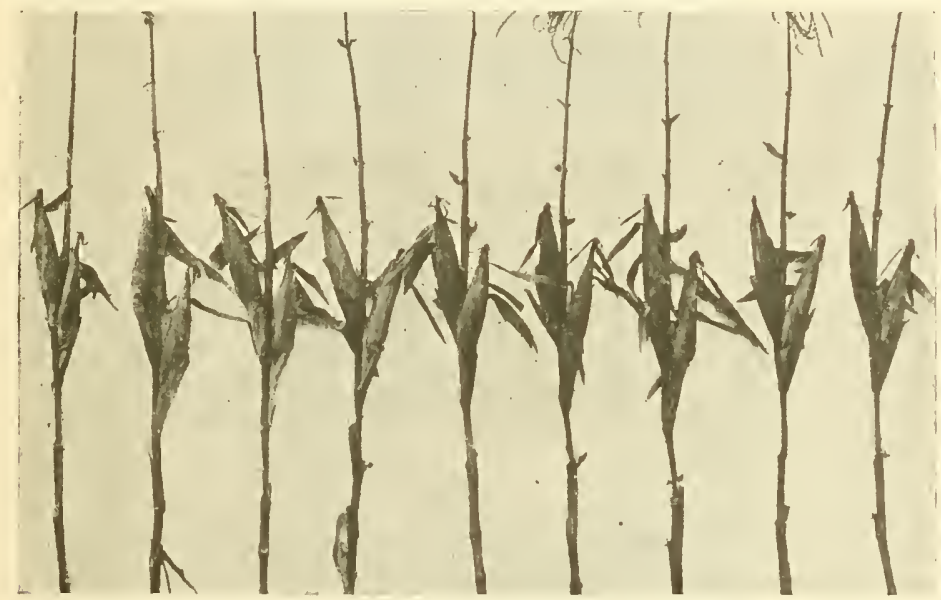

FIGURE 87. Redgreen sweet corn showing uniformity of earing.

with Evergreen inbred 77, the plants were notably uniform in growth. Nearly every plant had two ears that ripened at the same time. These cars were nearly always well filled to the tips. The color of the seeds was seen to be beautifully white and in tenderness, sweetness and flavor this combination was so much superior to ordinary sweet corn that it was grown in the home garden for table use.

This hybrid proved to be so productive and good in quality that a small amount of seed was produced in a crossing field in 1923. This seed was sent to various places for trial. A small quantity was grown by the IV. N. Clark Canning Company of Rochester, N. Y. It proved to be well adapted to that section and produced a superior product when canned. Production of crossed seed was soon started by the E. B. Clark Seed Company at Milford, Conn.

It has since been tested in many parts of the country and seems to be best adapted to southern New England and central New York and in certain sections of the Northwest, particularly Nevada and central Washington. Under exceptionally good growing conditions Redgreen has made 
three and four well filled ears on each stalk. The plants tiller freely and these increase production where there is no lack of water. Severe dry conditions coming after a period of luxuriant growth may curtail the

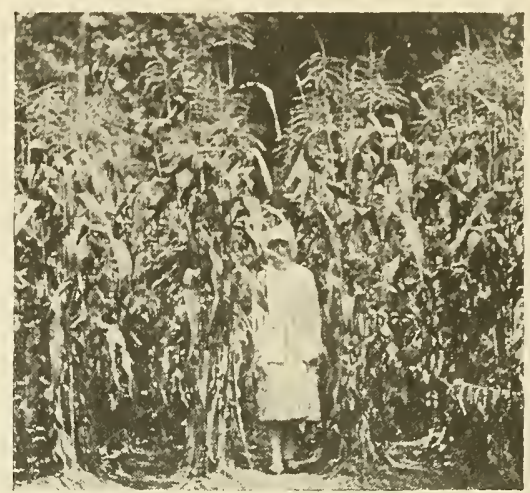

FIGURE 88. Redgreen growing in Connecticut.

formation of ears more severely than on other kinds of corn of the same season that do not tiller so freely.

The stalk growth and ear characters are shown in the accompanying illustrations. The plants grow from 6 to 11 feet tall varying with the

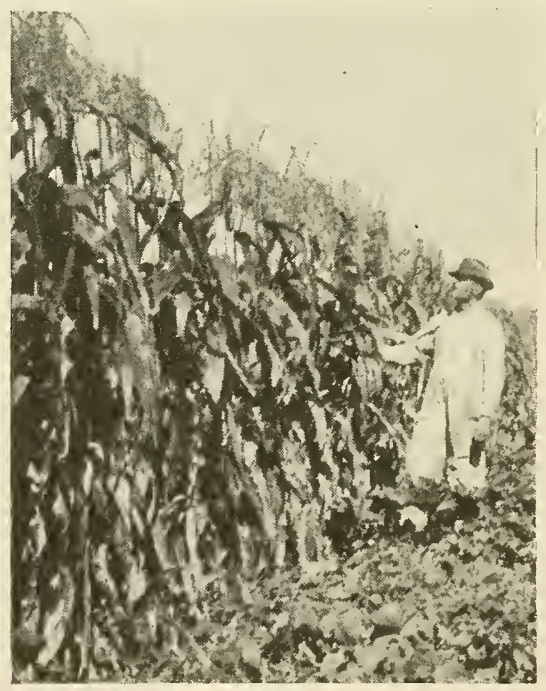

FIGURE 89. Redgreen growing in Nevada.

time of planting and growing conditions. About the time of tasseling, the plants begin to turn a brownish red that becomes darker as the plants mature. This color develops only in sunlight. The cob and kernels will 
also color if exposed to light. The glumes on the tassels are colored giving a field of Redgreen a characteristic appearance that can be easily recognized from a distance. The ears are mostly twelve-rowed, well filled to the tips, and well protected by long tight husks. The whiteness of the kernels and the tenderness of the hull are important features of this corn.

Redgreen is not adapted to localities south of Connecticut nor to the central states. It is susceptible to root rot and to bacterial wilt although it usually escapes damage on account of its late maturity. In time of ripening it is about the same as early Evergreen.

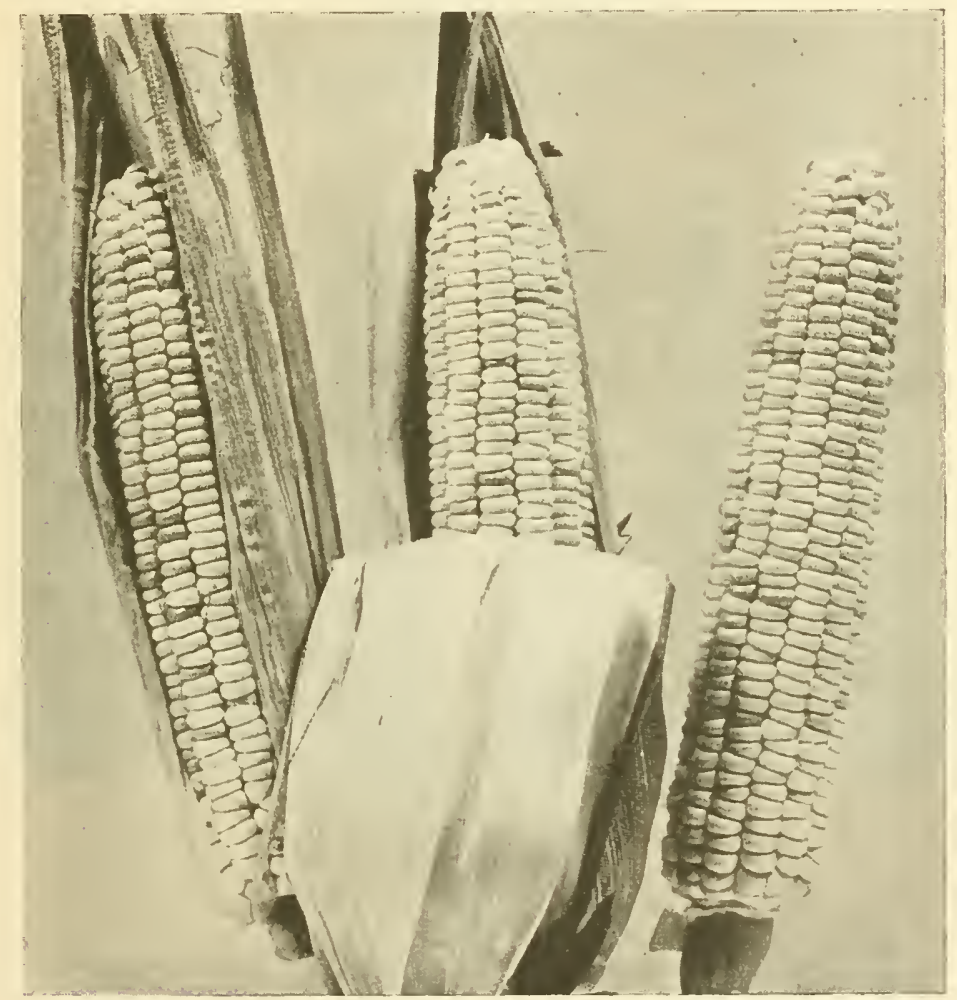

Figure 90. Ears of Redgreen at the eating stage.

The No. 77 pollen parent of Redgreen is a typical Evergreen with short cylindrical ears. There is a tendency to have more than one ear per stalk. The plants are without color in every part and are susceptible to smut and bacterial wilt. They are good pollen producers, the tassels maturing early, and numerous large tillers also increasing the amount and extending the time of pollen production. The ears are small, frequently smutted and moldy, and mature slowly. This inbred is generally used as the pollen parent. The outstanding characteristic of this inbred is the pure white color of the seeds. This quality it imparts to the cross together 
with a tender pericarp and other kernel features that go to make up good quality both for canning and for table corn.

The No. 75 inbred parent of Redgreen produces a single stalk from four to six feet high. Under favorable conditions it usually forms two small ears and sometimes three. The second ear often silks before the topmost ear. Shortly after silking the leaves, husks and glumes begin to color a brownish red wherever exposed to sunlight. The silks are red after exposure to light, the glumes on the tassels red, the anthers green.

The mature ears of this inbred are from three to five inches long with ten to twelve rows of small, round, finely wrinkled, glassy seeds. The tip of the ear often terminates in a small bare spike-like structure suggesting an abortive tassel. The pericarp has a tendency to crack as the seeds are maturing. This is especially noticeable when the seeds are crossed and should be guarded against by topping the plants and stripping
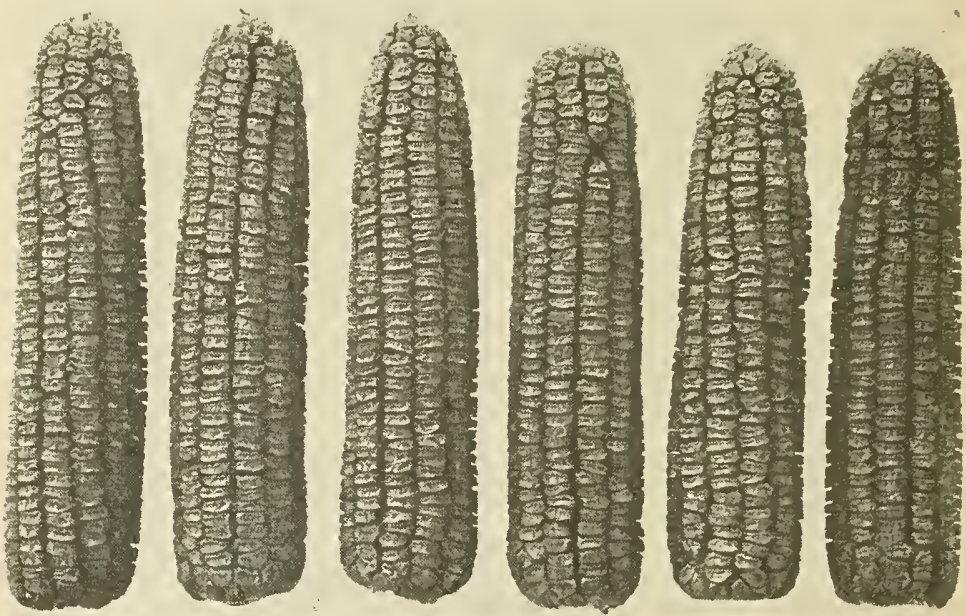

FIGURE 91. Ears of Redgreen at maturity showing uniformity of kernel type.

down the husks as soon as the cracking starts or before. The cracked seeds usually mold. This cracking is an indication of a tender pericarp.

In order to improve the general vigor, size of plant, and productiveness, this No. 75 inbred was crossed with Golden Giant, a yellow variety, and backcrossed to No. 75 for three generations, selecting yellow seed each time. After the third backcross and then selfing, the white seeds were planted and off-pollinated. This new white-seeded strain No. 78 gives similar results when crossed with 77 and has the advantage of being easier to grow and more productive. In appearance and uniformity it can hardly be distinguished from 75. A yellow-seeded strain similar in every respect except in color of seed was also established from the yellow seeds of the third backcross. This strain, numbered 85 , is used in the production of Yellow Cross. 


\section{Crosgreen}

Crosgreen is a first generation hybrid of Crosby corn with the No. 77 Evergreen inbred used in Redgreen. This white-seeded sweet corn is outstanding in early maturity and high production. The ears are often

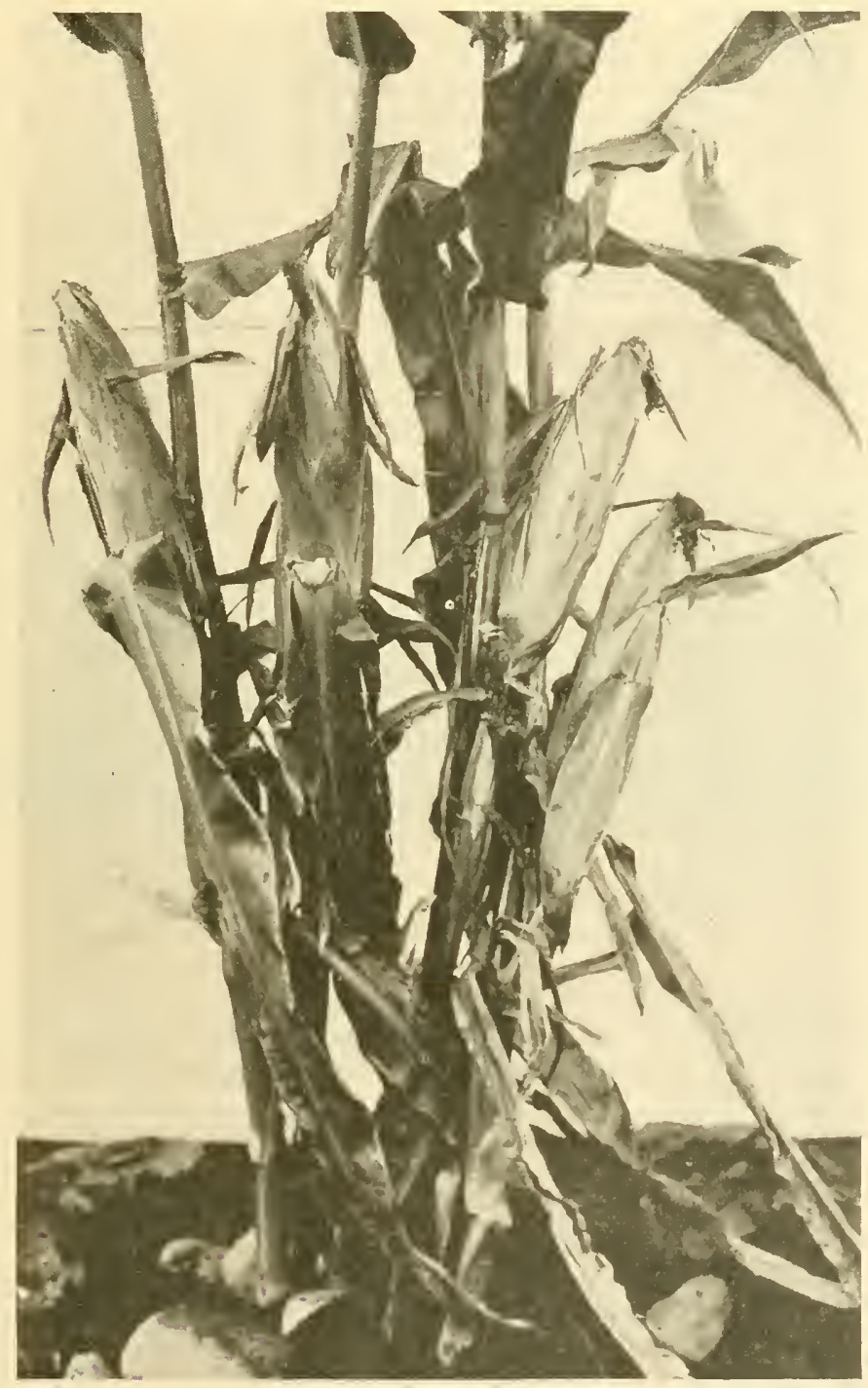

FIGURE 92. Crosgreen combines the quality and earliness of Crosby with some of the size of ear of Evergreen.

as large as Evergreen and mature a week or more earlier. For the seed parent several inbred strains obtained from the Maine Agricultural Ex- 
periment Station were used at first. These all seemed to give equally good results. In 1927, seven of these inbred strains were composited and used as a synthetic variety for a seed parent.

This stock of Crosby is so early that it is difficult to produce seed when Evergreen inbred No. 77 is used as the pollen parent. It has to be planted from three to four weeks later. When planted so late it does not give a good production of seed. This early Crosby is also quite susceptible to bacterial wilt. It has since been found that the top cross of No. 77 Evergreen on a naturally pollinated variety of Crosby of somewhat later maturity gives equally good results in yield and is nearly as uniform and early maturing.

Crosgreen produces one good sized ear to a stalk. The stalks are medium in height with a few medium sized tillers. The ears are long, cylindrical to slightly tapering with 14-18 rows of medium broad and deep kernels. The color is not so white as Redgreen but is satisfactory for canning. The quality and texture of the canned product compares favorably with Crosby. Its outstanding feature is the heavy tonnage of ears in those localities where it is well adapted and where bacterial wilt is not a serious factor.

Crosgreen was first produced in a crossing field in 1925 and sent out for trial the following year. The first commercial seed was grown by the E. B. Clark Seed Company in 1926.

\section{Yellow Cross}

This yellow inbred, No. 85, has been crossed with a number of yellowseeded inbreds of Evergreen type and season. No final selections have been made. This combination is a yellow-seeded Redgreen. The plants have the same reddish color. The first ear of most of these Yellow Crosses is larger than for Redgreen and there is less tendency to make second ears. The ears are well protected by long husks and the ears usually fill out well at the tips. The number of rows vary from 10-16, mostly 12.

Yellow Cross has not yet been generally tested but should be adapted to all sections where Redgreen is grown successfully. In season it is a little later than Golden Cross Bantam. The color and shape of the kernel is better for canning purposes. Quality and productiveness have not yet been tested.

\section{Green Cross}

The production of a first generation hybrid of inbred strains of Evergreen sweet corn was begun in 1921. About 50 open-pollinated ears of the Charles Treat strain of Stowell's Evergreen were self-pollinated. These 50 ears had been selected from 200 on the basis of a seed germination test showing them to be free from root rot infection. Later results have shown that this preliminary selection was probably a mistake.

The several lines were self-pollinated. Three progenies in each line were grown and the best appearing progeny at the time of pollination was selected for bagging. 
After several generations of self-fertilization six of the most promising lines were used as pollinators and crossed by hand-pollination on all of the lines except a few that had been discarded. The entire series of crosses was grown both at the Mount Carmel farm and at the Charles Treat farm in Orange. From this test about a dozen of the best combinations were selected for further testing. This was continued to the third year, final selection being made after the best combinations had been tested three years and in three different places in New Haven county the last year.

Based on all the results obtained the combination of 63 by 50 was selected and named Green Cross. This cross when at its best is remarkably uniform and large-eared. The stalks are large with a few tillers. There is very little color in any part of the plants. The ears are broad, cylindrical with a slight taper, usually filled out well to the tips. They have from 16 to 22 rows of kernels. The kernels are medium in width, and deep. The plants mature late but when well grown are remarkably productive. The corn is typically Evergreen in type.

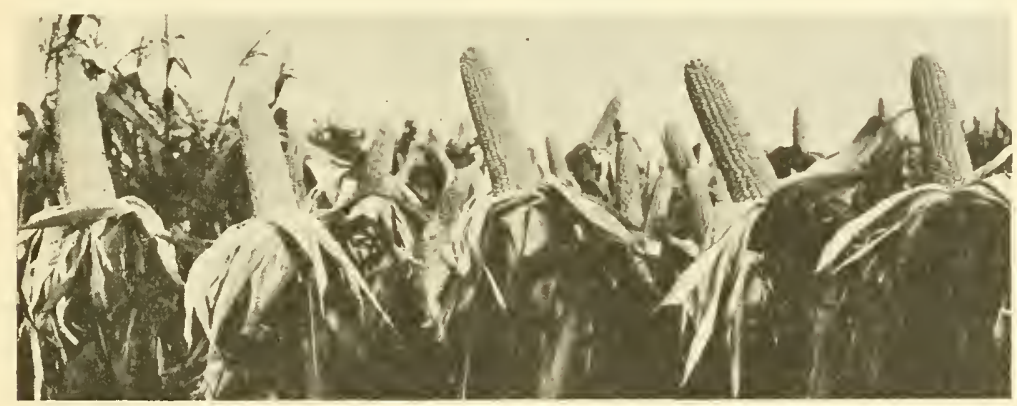

Figlre 93. Green Cross, a first generation hybrid of two inbred strains of Evergreen sweet corn.

Unfortunately this hybrid is not adaptable to sections outside of Connecticut and even at home develops a serious root weakness probably associated with root rot. The preliminary ear selection was based on plants that were free from infection. During the inbreeding process, the plants were grown on land that was rotated with other crops every two years and probably did not have much infection. This resulted in the plants not being subjected to disease and therefore they had no opportunity to show a resistance to this trouble. Green Cross is a striking example of the lack of adaptability of first generation hybrids between two uniform inbred strains. Where the plants do well and stand erect the uniformity of ear production and the size of the ears is truly remarkable as shown in the accompanying illustrations. Where there is a lack of fertility or moisture and the plants are unable to stand erect, the results may be very poor.

It should be noted that Green Cross is the first hybrid produced where the parental inbreds are both from the same variety, and in this case from the same strain of that variety. 
The Associated Seed Growers produced seed of Green Cross in 1929. They have since produced Evergreen combinations that are much more

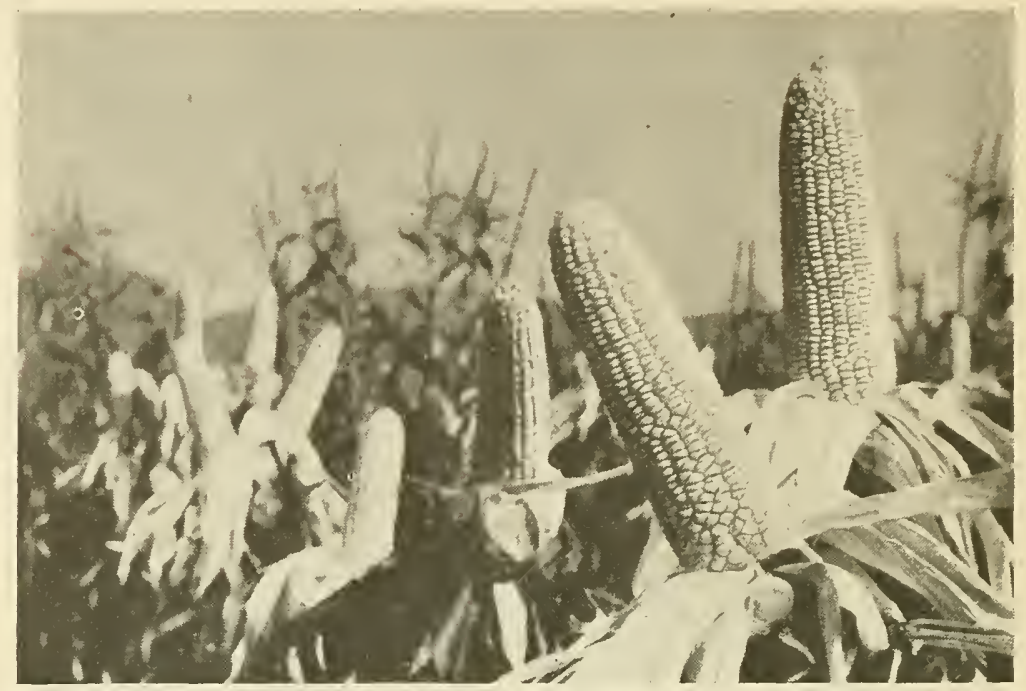

Figure 94. In size of ear Green Cross is outstanding.

adaptable over a wide territory and have the ability to stand erect under nearly all conditions. Other seedsmen have produced Evergreen hybrids that are more adaptable and productive over a wider range of soils and
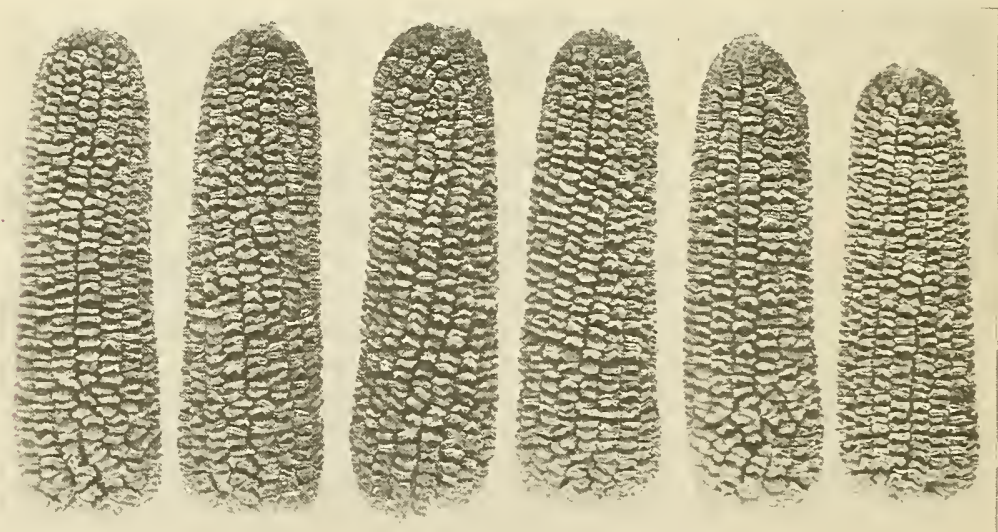

FIGLRE 95. The evenness in size and shape of kernel characteristic of crosses of two inbred strains is apparent in Green Cross.

seasons. No Evergreen sweet corn has yet been found that will produce larger ears than Green Cross when at its best. 


\section{Whipple Cross}

The sweet corn most generally grown for the market in southern New England is Whipple Iellow. This variety produces a large ear in the same length of time that Golden Bantam takes to ripen a small ear. It does not equal Golden Bantam in tenderness, sweetness or flavor but sells more readily on the general market to uncritical buyers who have not yet learned to appreciate quality. In this connection it should be noted that quality tends to disappear after corn has been picked for some time, so other things being equal, size is important. No other variety in this territory will produce as large and as attractive ears in the same time.

This variety originated with Silas S. Whipple at Norwich, Conn. He had been growing a local variety of white sweet corn having many rows

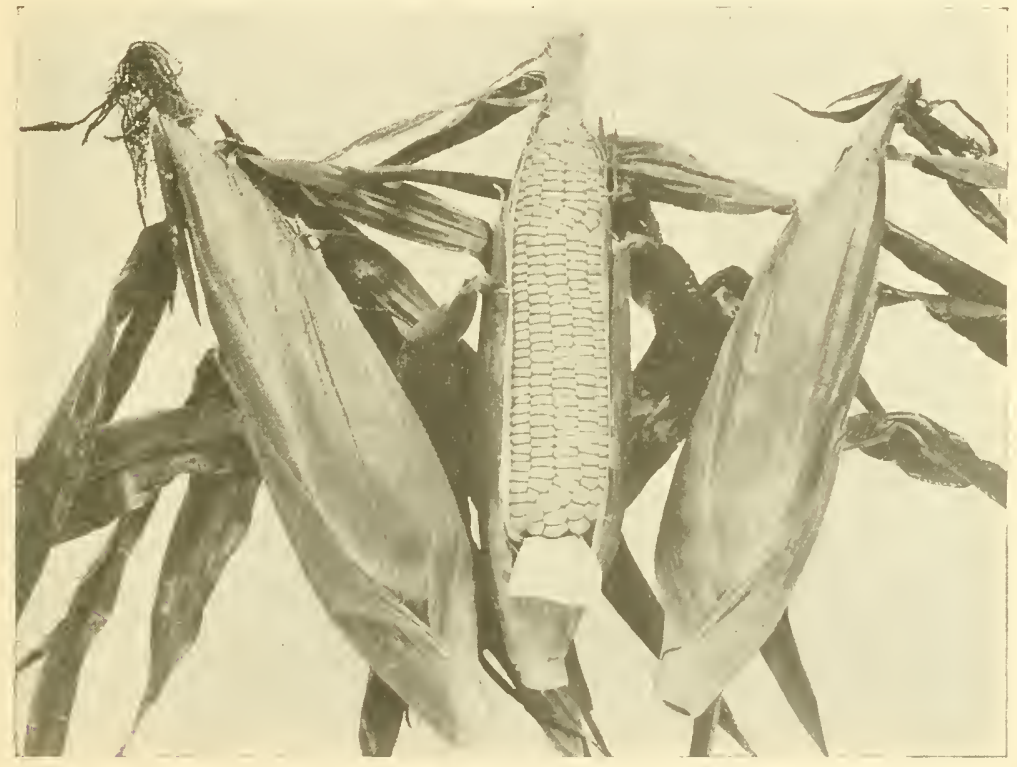

Figtre 96. Whipple Cross, like the variety from which it came, has the ability to make a large ear in a short time.

of kernels and maturing early. The origin of this corn is not known, but seems to have been developed locally. In 1913 this corn was crossed with Golden Bantam. The yellow kernels resulting from the mixed yellow and white ears were saved and the yellow color selected for five years until in 1918 the ears were nearly all pure yellow. The Harris Seed Company of Coldwater, $N$. I.. was among the first to appreciate the desirable qualities of this corn and make it available to market gardeners.

Mr. Thipple selected this variety for short, broad ears having many rows. His ideal was 18 to 20 rows on an ear not over 6 or 7 inches in length and many shorter. This corn was sold to the hotel trade where a short ear fitted easily in a side dish. As grown now, the Whipple variety usually has from 12 to 16 rows on ears from 7 to 10 inches long. 
From sced obtained from the originator and from a local market gardener the Connecticut Agricultural Experiment Station began selection in sclf-fertilized lines with this variety in 1925. After self-pollinating four or more generations the six most promising inbreds were crossed on all the other inbreds and on each other. After testing these combinations certain inbreds were noted to give good results in crosses and many combinations have been made among these and tested since the first crosses were grown in 1928. One of the best producers resulted from the cross of 12 by 2. The plants are medium in size with one good ear on every stalk. The uniform earing is an outstanding feature of this cross as shown in Figure 97.

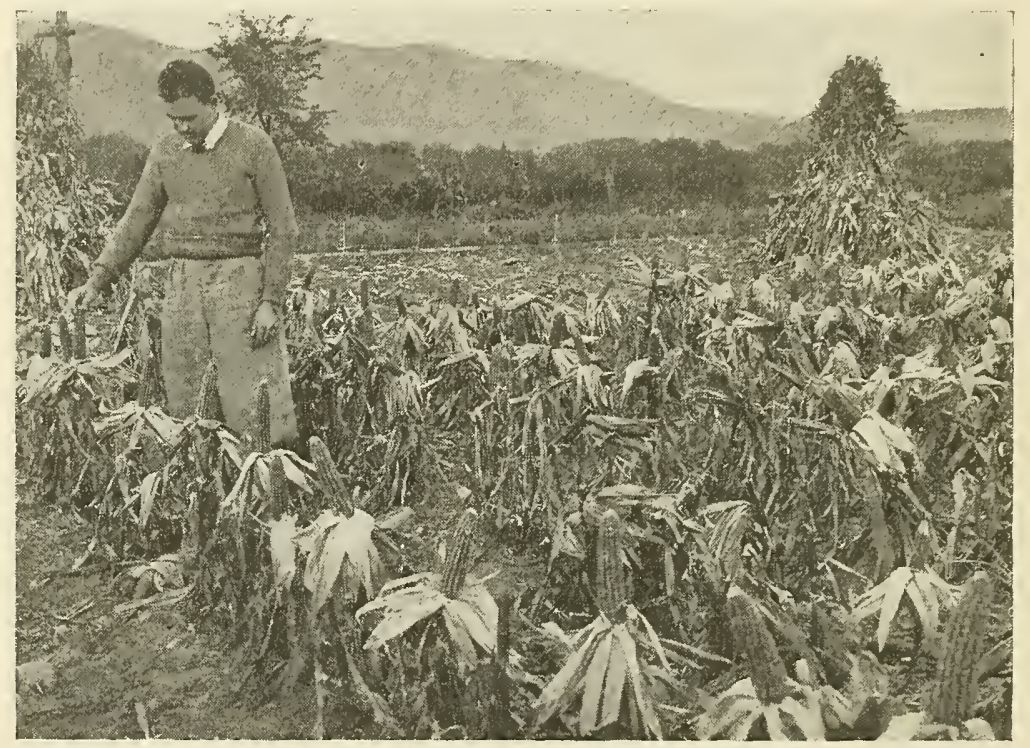

FIGURE 97. One good ear on every plant is characteristic of this cross of two inbred strains of Whipple corn.

When bacterial wilt became prevalent in 1932 it was quickly apparent that this combination was quite susceptible to the disease, so much so that it can not be used in wilt-infested territory.

The susceptibility of this combination comes amost entirely from the 12 inbred parent. Plants of this inbred are shown in Figure 13. growing alongside Purdue Bantam on one side and resistant Whipple on the other. It is notable that this inbred strain is injured much more than the variety from which it originated at the same time other inbreds are injured hardly at all. When grown free from wilt the 12 inbred produces a good stalk with a medium sized ear. It was one of the most productive of this series of inbreds until wilt appeared.

Whipple inbred 2 makes short, stocky plants with large, full tassels, seldom growing taller than four feet. There are usually from one to two well-developed tillers that also produce tassels that are well filled with 
pollen. The ears are small and poorly filled and usually mold badly: This inbred is not satisfactory as a seed parent but makes a fairly good pollen parent. It produces pollen over a period of a week or more. The plants are too short to distribute this pollen well but so far it has given good results.

This inbred is resistant to bacterial wilt. During the past two seasons it has made its usual growth in fields where wilt has been prevalent. Innoculation trials in the greenhouse have shown it to be resistant. It does not have the ability to overcome the susceptibility of 12 but other

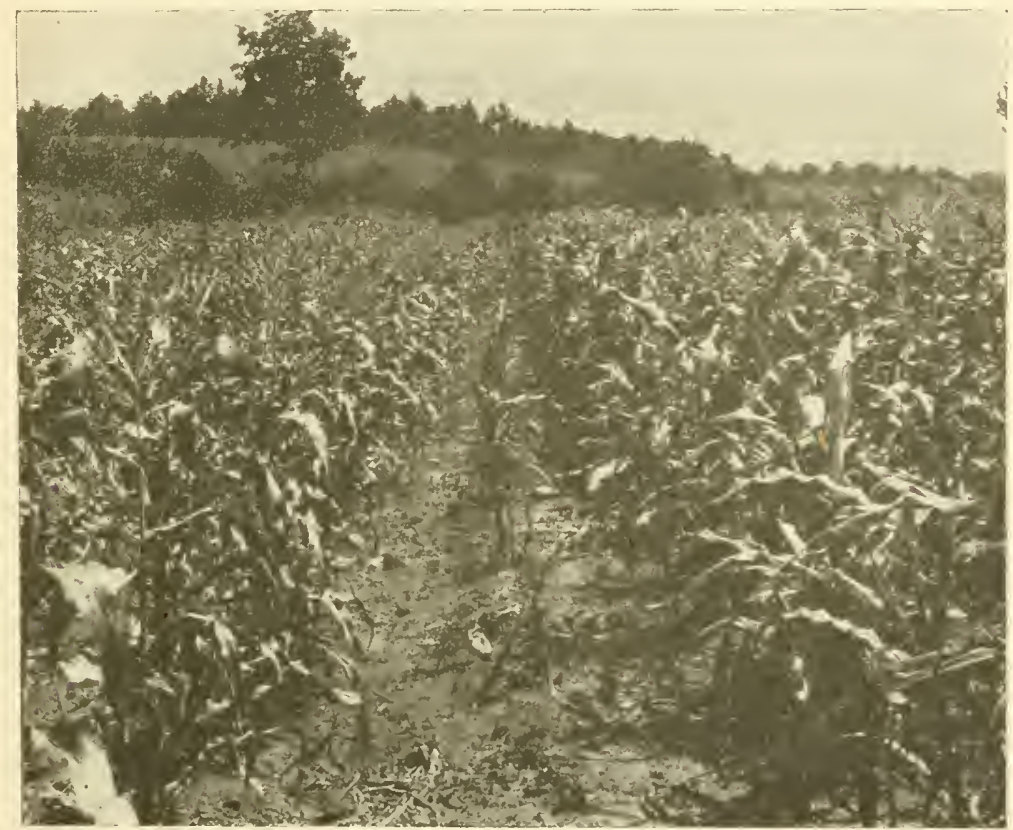

FIGLRE 98. An inbred strain of Whipple sweet corn, highly susceptible to bacterial wilt, growing between other strains that are free from serious injury.

crosses in which it has been tested in limited trials have shown no plants diseased.

Of all the inbreds grown this is the only one that is markedly susceptible to rust. Rust is rarely seen on corn and seldom injures vigorous plants to any noticeable extent in this region. This particular inbred is apparently quite susceptible. The disease develops late and apparently does not impair its ability to produce pollen. It does not produce welldeveloped ears under the best conditions and this production is considerably reduced when attacked by rust. Susceptibility to rust is apparently a recessive character since none of the $F_{1}$ hybrids with this inbred has shown this disease.

There are two inbreds that combine particularly well with 2. These are 6 and 7 . Both are free from serious injur by bacterial wilt and 
when crossed with 2 are uniformly well-eared and productive. Strain 6 produces medium sized, dark green plants with few tillers. The one ear per stalk is medium in size and usually well filled. The kernels are large, plump and dark colored, making this strain desirable as a seed parent. It works well when 2 is the pollen parent, the silks conning at the right time to receive the pollen when both are planted at the same time.

Strain 7 produces tall plants with few tillers. The ears are well filled and uniformly light-colored. The seeds are small and light in weight. It is not as good a seed parent as 6 . It also can be planted at the same time when 2 is the pollen parent.

The five best Whipple Crosses grown in 1933 compared with the original variety are as follows:

\begin{tabular}{|c|c|c|c|c|c|c|c|c|}
\hline Hybrid & $\begin{array}{l}\text { Ave. Mate } \\
\text { of Silking } \\
\text { in July }\end{array}$ & $\begin{array}{l}\text { Percent } \\
\text { Wilted } \\
\text { Plants }\end{array}$ & $\begin{array}{l}\text { Ear } \\
\text { Length } \\
\text { In. }\end{array}$ & $\begin{array}{l}\text { No. of } \\
\text { Rows of } \\
\text { Grain }\end{array}$ & $\begin{array}{l}\text { Ave } \\
\text { Ne } \\
\text { Miktble. }\end{array}$ & $\begin{array}{l}\text { No. ears } \\
\text { plant } \\
\text { Not mktble. }\end{array}$ & \multirow{2}{*}{$\begin{array}{l}\text { Ave. wt. o } \\
\text { irktble. ear } \\
\text { in lbs. } \\
\text { per } \\
\text { plant } \\
.23 \\
.28\end{array}$} & $\begin{array}{l}\text { of } \\
\text { ars } \\
\text { per }\end{array}$ \\
\hline $\begin{array}{l}6 \times 2 \\
6 \times 9\end{array}$ & $\begin{array}{l}26 \\
23\end{array}$ & $\begin{array}{l}0 \\
0\end{array}$ & $\begin{array}{l}7 \\
7.5\end{array}$ & $\begin{array}{l}12-16 \\
10-14\end{array}$ & $\begin{array}{l}.94 \\
.88\end{array}$ & $\begin{array}{l}.38 \\
.25\end{array}$ & & $\begin{array}{l}\text { ear } \\
.24 \\
.32\end{array}$ \\
\hline $\begin{array}{l}2 \times 7 \\
7 \times 24\end{array}$ & $\begin{array}{l}24 \\
26\end{array}$ & $\begin{array}{l}25 \\
18\end{array}$ & $\begin{array}{l}7 \\
7\end{array}$ & $\begin{array}{l}12-16 \\
12-18\end{array}$ & $\begin{array}{l}.81 \\
.62\end{array}$ & $\begin{array}{l}.62 \\
.44\end{array}$ & .22 & .27 \\
\hline $\begin{array}{l}5 \times 2 \\
\text { Whipple variety }\end{array}$ & $\frac{27}{28}$ & $\begin{array}{l}13 \\
18\end{array}$ & $\begin{array}{l}7.5 \\
6.5\end{array}$ & $\begin{array}{r}12-16 \\
8-14\end{array}$ & $\begin{array}{r}1.00 \\
.81\end{array}$ & $\begin{array}{l}.62 \\
.25\end{array}$ & $\begin{array}{l}.32 \\
.18\end{array}$ & $\begin{array}{l}.32 \\
.23\end{array}$ \\
\hline
\end{tabular}

All produced a greater total weight of marketable ears than the original variety and these ears averaged heavier. All but one cross produced the same or more marketable ears per plant. All crosses ripened as early or earlier. Other hybrids produced equally good results or better in some respects than the two described above. All crosses with $24^{\circ}$ produce large ears but these are not well filled at the tips. This inbred is also not satisfactory either as a seed parent or as a pollen parent. Strain 9 and 5 have not been tested sufficiently to know what they will do under varied conditions but from the one year's results in combination with 2 and 6 , they are promising. These strains will be tested further. All things considered, $6 \times 2$ and $7 \times 2$ are the best Whipple single crosses obtained sa far.

\section{Other Sweet Corn Crosses}

The most widely grown sweet corn cross at the present time is probably Golden Cross Bantam, a product of the United States Department of Agriculture and the Indiana Agricultural Experiment Station. This is a first generation hybrid of two inbred strains considerably different in type. Its history and description are given in circular 268 from the United States Department of Agriculture.

Golden Cross Bantam has been grown at the Mount Carmel farm since 1930. Every year it has produced a good crop of crlindrical, well filled ears, mostly twelve rowed. There is always one and often two good ears on each plant. In some years under dry conditions the second ear fails to set seed. In tenderness and sweetness this corn is equal to the best Golden Bantam. It is also markedly resistant to bacterial wilt. The plants 
at an early stage may show some infection but later they have the ability to grow out and show very little injury.

As a market garden corn Golden Cross Bantan is too late in maturity to sell to the best advantage. The ears are slender due principally to a small cob and tight fitting husks. The average weight of the mature dry ear is slightly more than for IVhipple but it appears to be a much smaller ear at the eating stage.

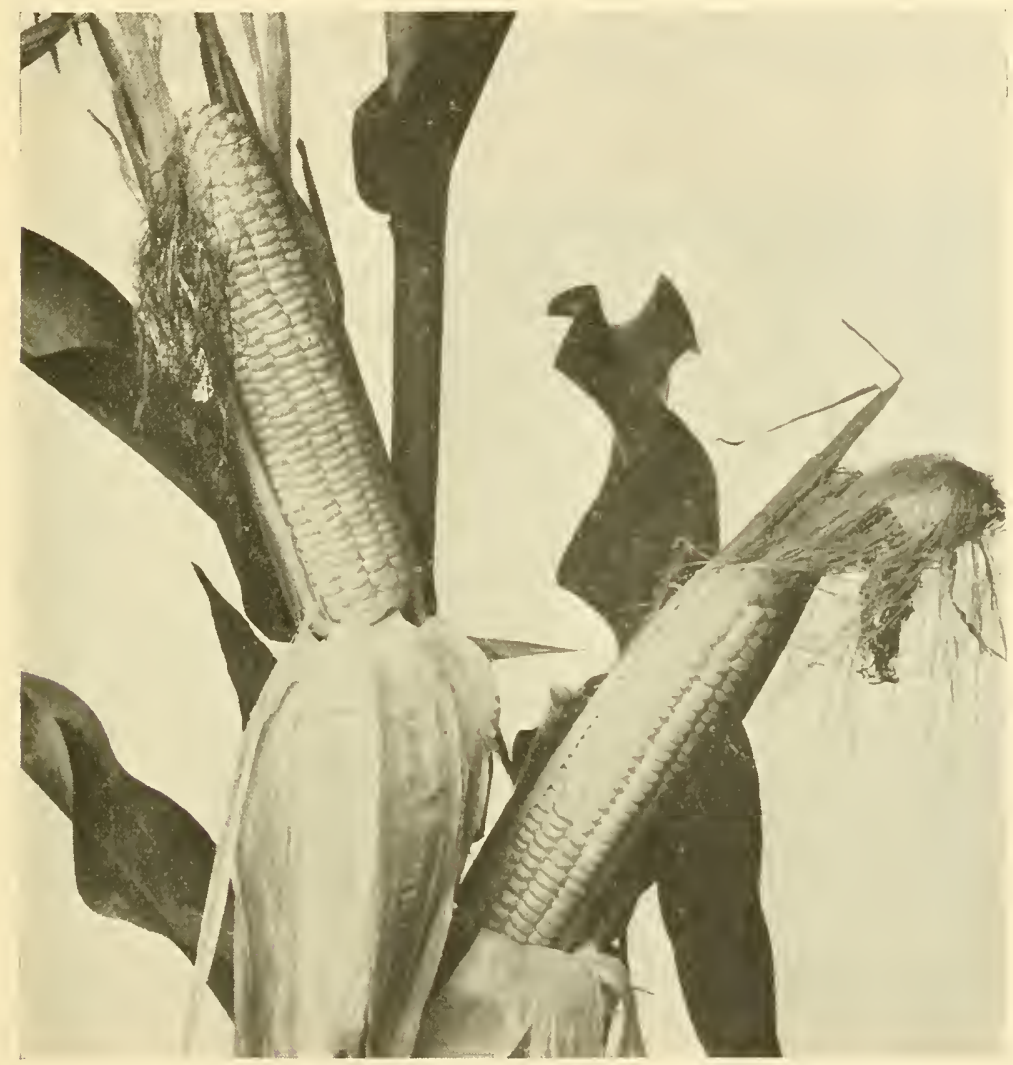

Figtre 99. Golden Cross Bantam usually produces two marketable ears on each stalk. (Photograph from the Robson Seed Farms, Hall, N. Y.)

The ontstanding feature of Golden Cross Bantan is its wide adaptability as shown by its good performance in many parts of the country. It has yielded well from Maine to Illinois and is one of the most promising yellow sweet corns in the principal canning regions. Very few first generation hybrids of two inbred strains of either sweet corn or field corn have the ability to grow so well in such varied soils and climatic conditions. It seems to be well suited to Connecticut where in many trials it has produced the most marketable ears of any yellow sweet corn of which seed is available at the present time. 
Golden Cross Bantam is the product of Purdue inbred No. 51 as the pollen parent and Purdue No. 39 as the seed parent. Purdue 51 is an eight and ten rowed strain of Golden Bantam type. The plants are short, tiller freely and produce a good supply of pollen over a period of several days. This inbred strain is somewhat susceptible to hacterial wilt. Purdue 39 has a short thick stalk and few short tillers with from one to three well filled ears. These ears have from ten to twelve rows, are cylindrical, and well filled to the tip. The kernels are small and light in color. This inbred strain often produces more corn than many open-pollinated varieties of Golden Bantam and has been used as a variety. It is not typically Golden Bantam in type but has the same tenderness of pericarp, and in sweetness and flavor it also compares quite favorably with Golden Bantan.

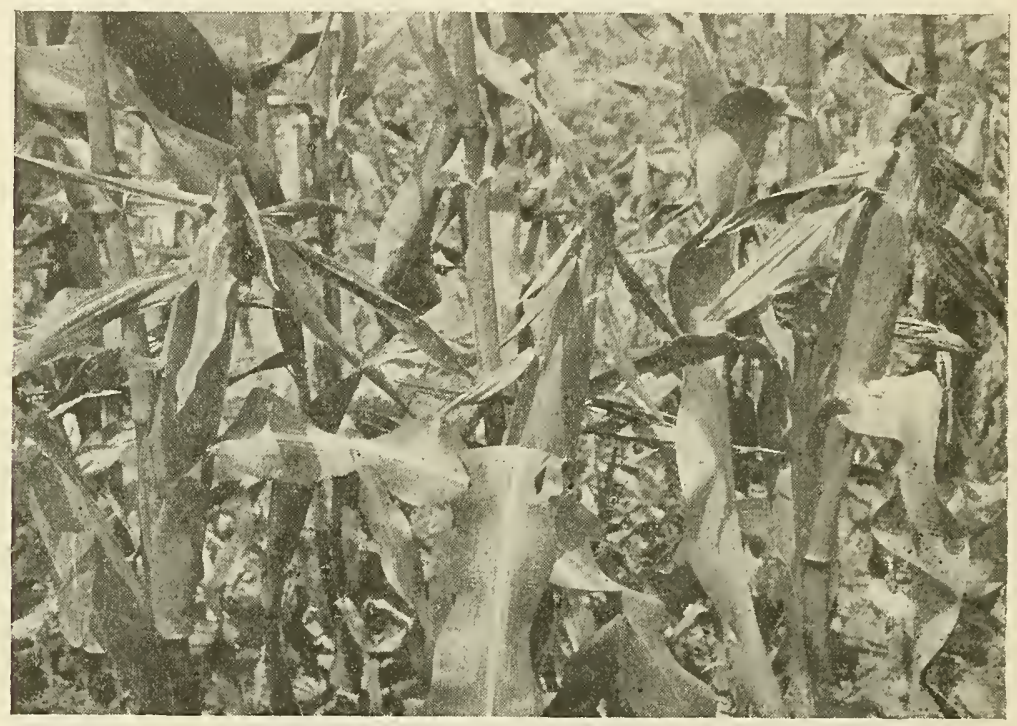

Figure 100. The ears of Golden Cross Bantam are long and slender with tight fitting husks.

This inbred combines well with many other kinds of corn. It has been used as a pollen parent to top cross on several varieties, one of which is Sumshine. This cross is more uniform and productive than Sunshine but ripens later. While it is appreciably less injured by bacterial wilt than the parental variety it is far from immune.

The top cross of Purdue 39 on Spanish Gold in 1933 produced more than 10,000 marketable ears per acre compared with 7,000 for Top Crossed Sunshine and 2,000 for Golden Early Market, under conditions of severe wilt infection. The first ears were picked three days earlier than Top Crossed Sunshine and five days after Golden Early Market. The ears are well filled to the tips, long and slender, mostly with ten rows. This cross is somewhat difficult to produce on account of the wide difference in time of flowering. The Spanish Gold seed parent must be planted about three weeks after the pollen parent and when planted so late does not 
make as good growth and yield of seed as when planted at the normal time.

The top cross of Purdue 39 on Whipple Yellow is outstanding in yield of large well-filled ears. The comparison with the variety itself and with Golden Cross Bantam is as follows:

\begin{tabular}{|c|c|c|c|c|c|c|c|}
\hline $\begin{array}{l}\text { Variety } \\
\text { or } \\
\text { cross }\end{array}$ & $\begin{array}{l}\text { Ave. Date } \\
\text { of Silking } \\
\text { in July }\end{array}$ & $\begin{array}{l}\text { Percent } \\
\text { Wilted } \\
\text { Plants }\end{array}$ & $\begin{array}{l}\text { Ear } \\
\text { Length } \\
\text { In. }\end{array}$ & $\begin{array}{l}\text { No. of } \\
\text { Rows of } \\
\text { Grain }\end{array}$ & $\begin{array}{l}\text { Ave. } \\
\text { pe } \\
\text { Mktble. }\end{array}$ & $\begin{array}{l}\text { No. ears } \\
\text { plant } \\
\text { Not mktble. }\end{array}$ & $\begin{array}{l}\text { Ave. wt. } \\
\text { Mktble. ear } \\
\text { in lbs. } \\
\text { per }\end{array}$ \\
\hline 1. & 28 & 19 & & & .81 & .2 & .18 \\
\hline ipple $x$ Purdue 3 & 3928 & 6 & 7.3 & $10-14$ & 1.25 & .19 & .34 \\
\hline olden Cross Banta & $\operatorname{am} 32$ & 19 & 7 & $8-14$ & 1.06 & .81 & .28 \\
\hline
\end{tabular}

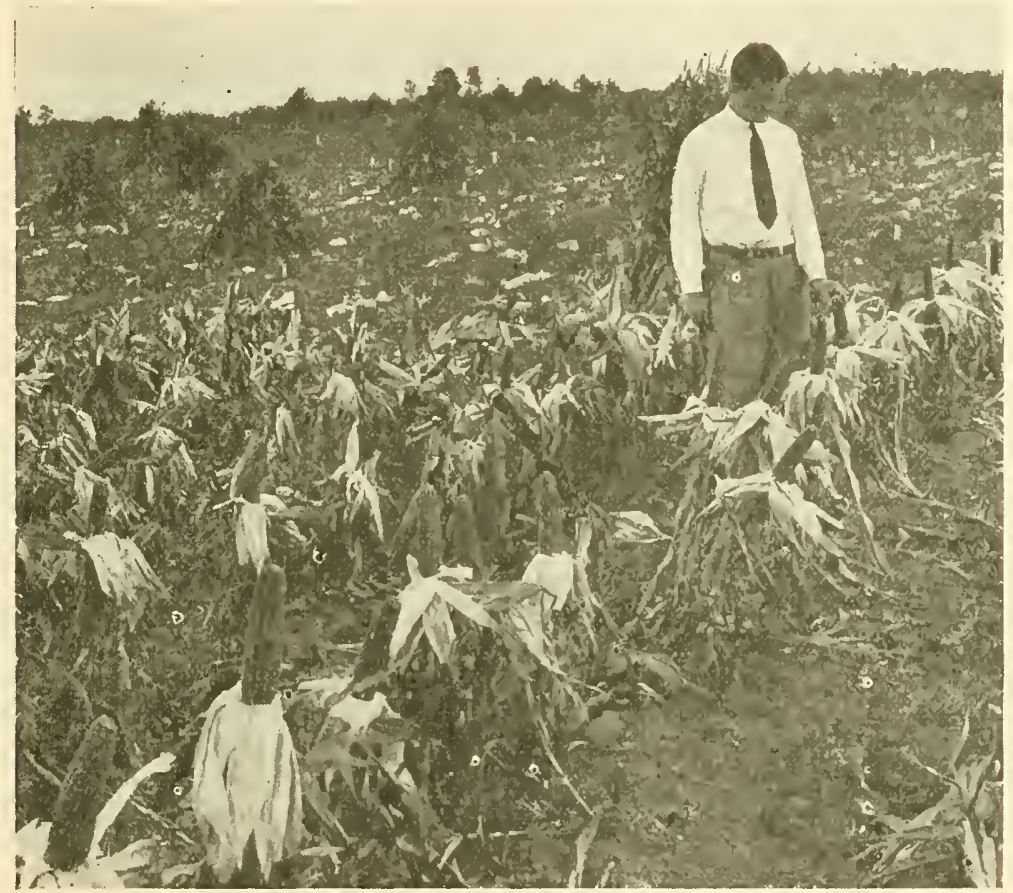

FIgURE 101. The uniformity in size and shape of ear is a regular feature of Golden Cross Bantam.

In season this top cross is earlier than Golden Cross Bantam, produces more marketable ears and these ears average larger in size and somewhat heavier. Although it has been tested only one year it seems to be as resistant to bacterial wilt as Golden Cross Bantam. It should be adapted to all sections where the Whipple variety is grown successfully. Considering its probable wide usefulness and ease of producing seed this combination seems to be one of the best in its season.

Many new sweet corn crosses are being produced by the Agricultural Experiment Stations in the corn growing states and by seedsmen. The Associated Seed Growers, Landreth Seed Company, Northrup, King and 
Company and several sweet corn canning companies have taken a leading part in the production of valuable new sweet corn combinations.

\section{The Froduction of Inbred Strains}

One of the results of the increased use of cross-bred sweet corn is an active interest in the production of inbred strains. Some of the principles involved and the results obtained are discussed in Bulletin 266 of this station. It has been found that self-fertilization for three or four generations brings about enough uniformity and fixity of type in some lines to give worthwhile results and that further close inbreeding is not desirable.

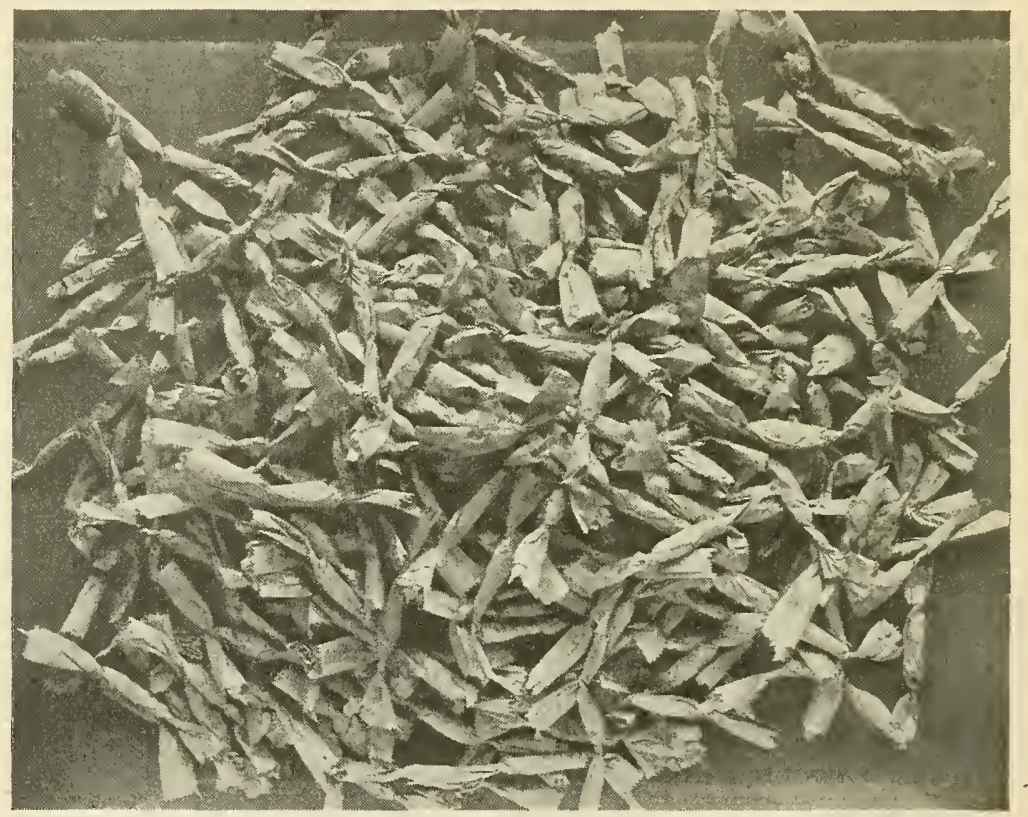

FIGURE 102. The seeds in these 322 tissue paper wrappers are planted in hills, each lot represents one inbred line.

It is important to have as many inbred strains as possible to select from. Selection during the first few inbred generations is effective in establishing specific characters not associated with reproductive ability, but selection for productiveness is of little value because this is so closely associated with hybrid vigor that the selection of vigorous and productive plants for progenitors of the inbred lines merely delays the reduction to uniformity. Unless other characters such as time of maturity, color, shape of ear, kernel characters or disease resistance are more important the best procedure is to grow only a few plants in each line and pollinate only enough to make sure of seed to continue the line. These pollinations are made mostly at random, using normal healthy plants of the type desired. In this 
way it is possible to produce a large number of inbred lines on a small area with a minimum of labor of hand-pollination. Some of these lines when tested should be found to give desirable results when crossed.

One method that we have used is to plant one ear to a hill. Six seeds are taken from each ear, wrapped in tissue paper and one packet dropped by hand in each hill. The hills are thinned to three stalks, and two ears in each hill are hand-pollinated. At harvest both ears are examined, but only one is saved. This is continued for three generations. Each ear represents one line. No individual labelling of the lines is necessary at any time. In this way a large number of inbred lines are available for selection after homozygosity is reached. In the fourth or later generations enough plants can be grown to have an estimation of the line's worth although it is possible to obtain some idea from a single hill.

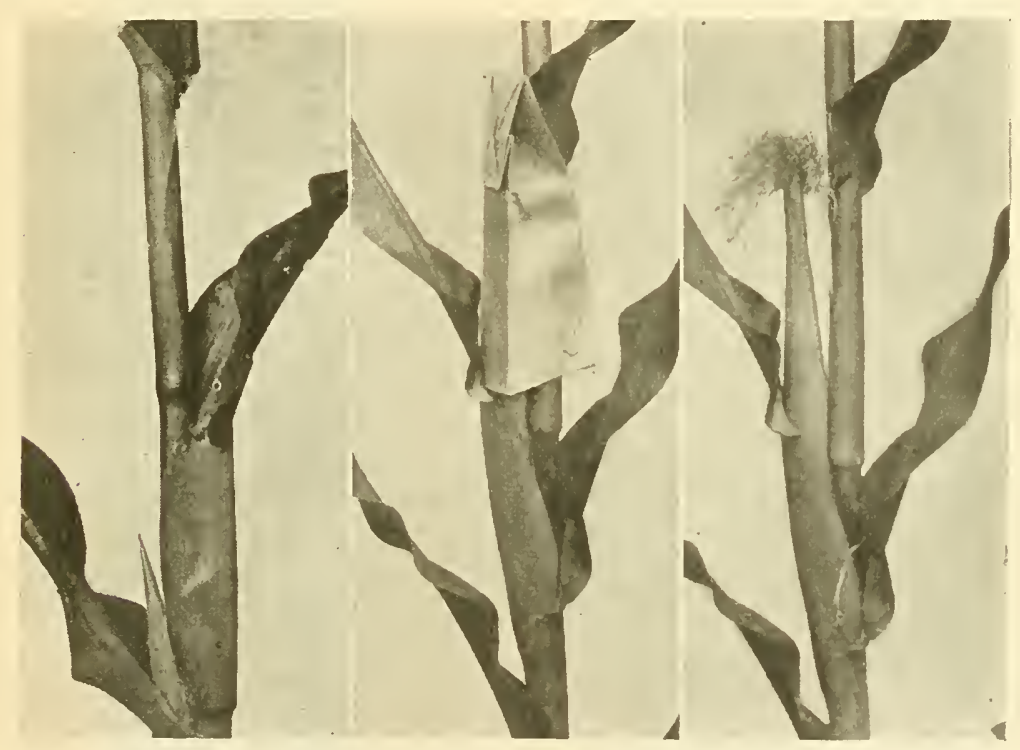

FIGLRE 103. Ear shoot ready to bag, bag in place, and ear shoot showing silks ready to pollinate.

Theoretically there is a possibility of better recombination of characters when the inbreeding is done by sib mating (one plant pollinated by another in the same progeny) than by self-fertilization. Off-pollination is more easily performed than self-pollination. The plants are less injured by the manipulation of bagging when only one bag is used and the silks and tassels can be selected to come more nearly at the same time. This is especially worthwhile with very early corn that makes small plants after they are inbred for a few generations. A report on the results obtained from sibpollinated lines will be given later. It is sufficient to say here that it is a promising method of procedure, one that gives inbred strains that are not too much reduced in vigor. 


\section{The Technique of Hand-Pollination}

In securing inbreds of corn it is of course necessary to hand-pollinate cach year all of the ears that are used for seed. To be sure that all foreign pollen is kept out the ear shoot must be covered before any silks appear and likewise we must protect the tassel so that foreign pollen does not lodge on it to be carried to the silks when the pollination is made.

Manilla bags are used for both tassels and ears. An eight pound strong

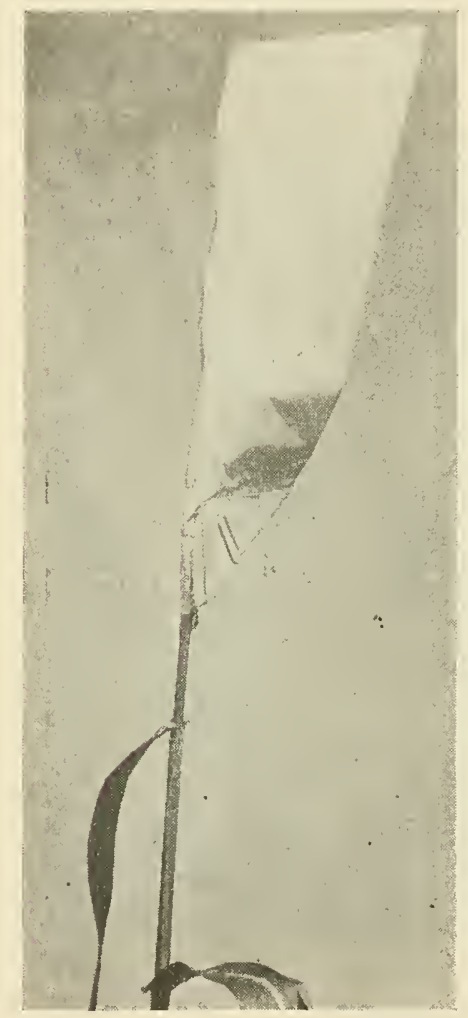

Figure 104. Bag on tassel. The upper leaf is usually removed.

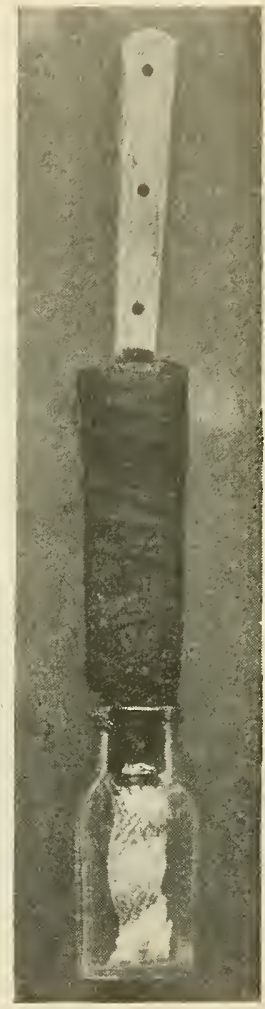

FIgURE 105. Sheath to hold knife. Two flat lamp wicks sewed together at their edges and covered with tape, the lower end immersed in alcohol, keep the knife blade sterile.

V-bottom bag is fastened orer the tassel, while a square bottom three pound nail bag covers the ear. The ear bag is applied with the bottom of the bag still folded so as to afford extra protection to the developing ear shoot. An ear just ready for bagging and one with bag in place may be seen in Figure 103. A tassel just bagged is shown in Figure 104. Both the tassel and ear bags are secured with paper clips. 
The ear bag is applied any time before the silks emerge, but usually as soon as the ear shoot appears. The tassel bag is put on about the time the main spike begins to shed pollen. Pollen is not gathered from this bag for at least 24 and preferably 48 hours. This allows sufficient time for any foreign pollen lodged on the tassel to become inviable.

The proper time for making the pollination to obtain a full set of seeds is when the silks have just formed a brush about two inches long (Figure 103). If the silks have grown longer, they are difficult to pollinate and are likely to hang below the bag. They may be cut off with a sterile knife, before pollinating, care being taken not to touch with the hand the silks to be pollinated. This can be accomplished by grasping the outer end of the silks while cutting and then throwing away the portion held (Figure 106). It is comparatively simple to keep a knife sterile by always carrying it in a sheath made with two lamp wicks wrapped with electrician's tape. The lower part of the wick extends into a small bottle filled with alcohol

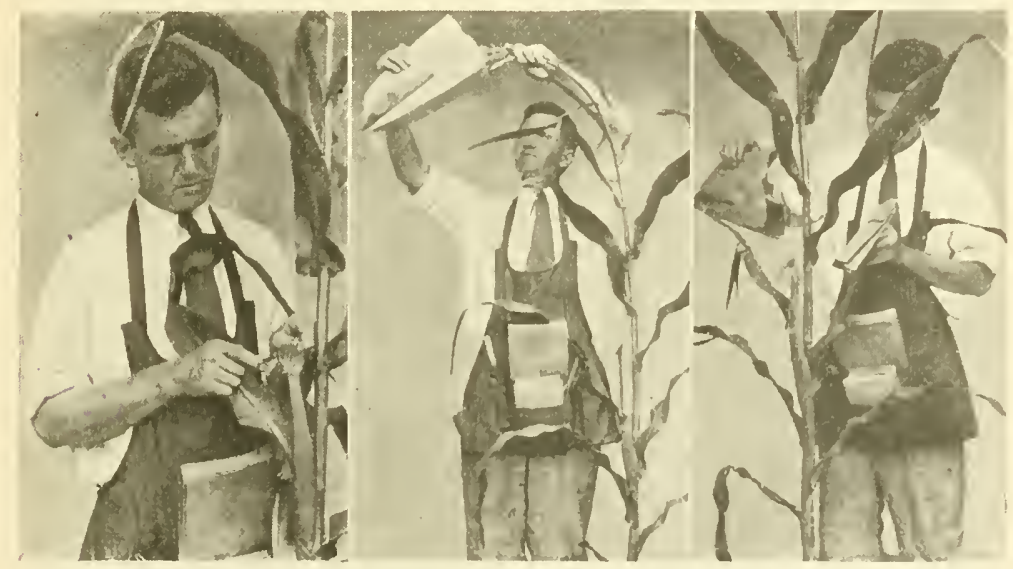

FIGURE 106. Cutting silks, shaking pollen into tassel bag, and dusting this pollen over the cut silks.

(70-95 per cent). See Figure 105. The sheath around the knife is moist with alcohol and keeps it sterile. It is held in a special pocket in the pollinating apron (Figure 106). The pollinating apron also provides separate pockets for tassel bags, ear bags, paper clips, and pencils.

It is best to do the pollinating as quickly as possible in order to avoid contamination from pollen in the air. Another safeguard against contamination is to hold the ear bag directly over the ear while completing the operation. Probably the most important precaution to avoid contamination is, so far as possible, not to make pollinations for an hour or more in the morning, when most of the pollen is being shed. Ten o'clock is about the time of maximum pollen shedding. If the work can be arranged so that ear and tassel bags may be put on at this period and pollinations made later in the day, considerable contamination will be avoided. Then, too, the tassels on the stalks to be pollinated can be pulled out before pollination, provided they will not be needed later for pollen. 
After pollination the ear hag is replaced over the ear and then the tassel bag over that. Both are secured by one paper clip. The two bags afford extra protection for the developing ear, especially needed during windy, wet weather. Before the ears are ready to harvest the pedigree of the

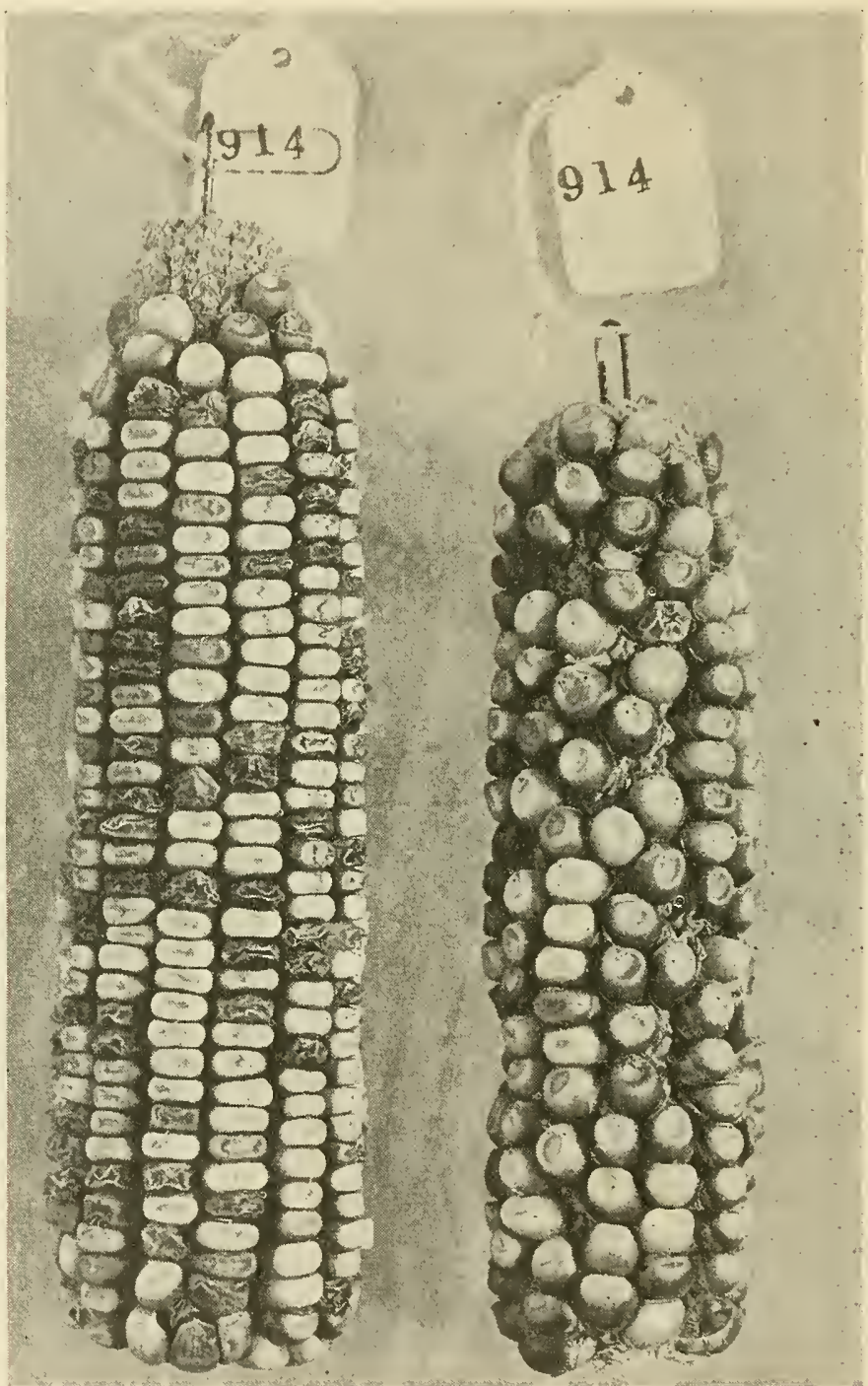

Figure 107. Hand-pollinated ears labeled to show pedigree.

cross or self is put on a small string tag which is fastened to the paper clip. When the ear is harvested one prong of the clip is straightened and stuck into the end of the ear (Figure 107). The ears are then dried by 
putting only a single layer in wire crates (Figure 108). Crates are $16 x$ $30 \times 7$ inches outside dimensions and hold about one bushel. They are mouse proof since each crate forms a lid for the one below when stacked.

\section{Multiple Pollinations}

It is often desirable to make a large number of pollinations from a small amount of pollen. This often happens when a common pollinator is used for a whole series of crosses. Several schemes have been devised to accomplish this. The insect powder gun is used by some. A modification of a glass atomizer is also employed for this purpose. The objection to these pollinators is that they have to be sterilized when changing pollen. A simple inexpensive pollinator can be made from a small glassine bag, $21 / 2 \times 6 \frac{1}{2}$ inches, the one used for ear bags by a good many workers.

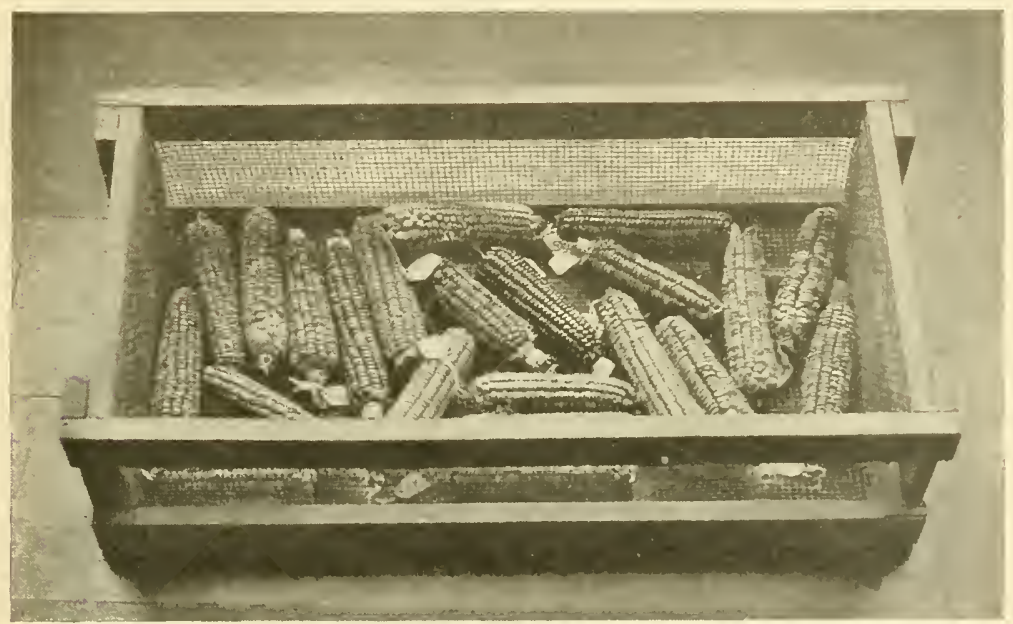

FigCRE 10S. Hand-pollinated ears in a wire crate used for drying.

A fresh bag can be utilized for each batch of pollen and then discarded. If the bag is creased crossways about half way up, the pollen and anthers can be poured into the top half. Then by gently tapping the bag at the crease the pollen alone will run down into the lower half. When all the pollen is thus transferred, the anthers are dumped out and the top folded over. A paper clip is used to fasten the bag. By cutting off one corner of the bag containing the pollen, the pollen is shaken out much the same as from a salt shaker. By this method as many as 30 to 50 pollinations have been made from the pollen of a single plant.

Another method of making multiple pollinations is to cut a small hole in the tassel bag after the pollen has been collected and use the tassel bag as a "salt shaker" without removing the anthers. This is simpler than the glassine bag method and is recommended in case only 10 or 20 pollinations are desired from each pollinator plant. 


\section{Production of Crossed Seed in Field Plots General Method}

After the inbreds have been secured and by crossing them we have obtained the corn we desire, we are faced with the problem of producing crossed seed in quantity. The object is to get all of one specified inbred or variety pollinated by another given inbred. This is comparatively simple in corn, since the male and female inflorescences are on different parts of the plant. If the seed parent is planted in every other row and the pollen parent in the alternate rows, we can obtain crossed seed by pulling out all of the tassels of one at pollinating time. The detasseled plants will then be pollinated by the other. For example, if we wish to make a cross of Spanish Gold x Connecticut 2 (a Whipple inbred) we would plant these two strains in alternate rows and then remove all the tassels from the Spanish Gold. All the seed produced on the Spanish Gold must then be crossed by Connecticut 2. The seed produced on the Connecticut 2 is selfed or sib-pollinated and represents an increased lot of this inbred.

In this crossing plot the Spanish Gold is desiginated as the seed parent or female ( $q$ ), while the Connecticut 2 is the pollen parent or male $(\hat{o})$.

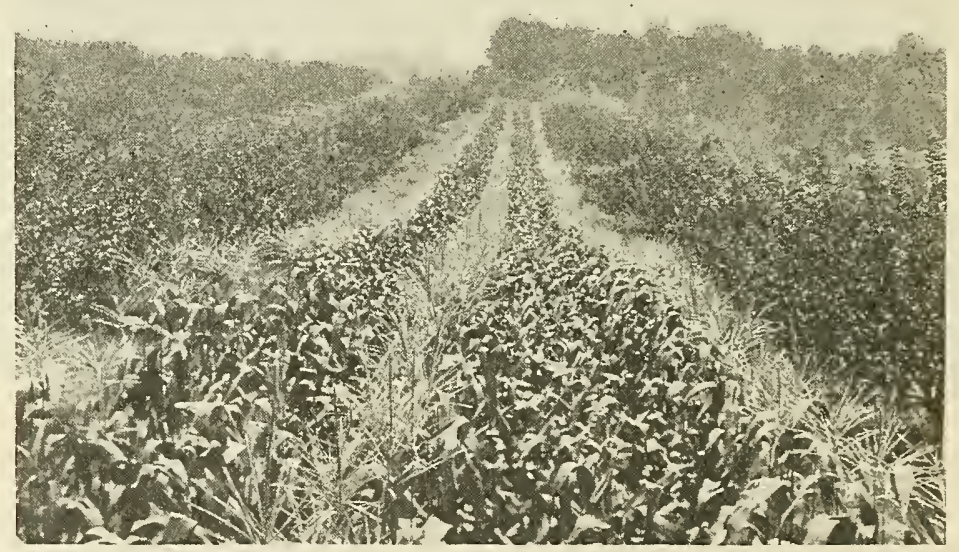

Figure 109. Crossing plot showing alternate rows detasseled.

\section{Number of Rows of Seed Parent and Pollen Parent}

If we grow an equal number of rows of both the seed parent and the pollinator, a yield of crossed seed will be obtained from only one half of the acreage grown. Thus two acres in a crossing plot will give one acre of crossed seed and one of the pollinator. A low yield of crossed seed to the acre will be obtained. If we can increase the number of rows of the seed parent in comparison to the pollen parent greater yields of crossed seed can be produced. Care must be taken not to plant too many rows of the seed parent to one of the pollen parent; a poor pollination 
will result if the proportion is not right. Most of the inbreds put out by the Connecticut Station as male parents will produce sufficient pollen for three to four times as many rows of the female parent. In the production of Redgreen seed complete pollination has been obtained when five rows of Connecticut 75, the seed parent, have been planted with one row of Connecticut 77, the pollen parent. However, we do not recommend more than four rows of the seed parent to one of the pollen parent. Growing them in this proportion, four-fifths of the acreage in a crossing plot will result in crossed seed. The inbred Connecticut 2 is a good pollinator and one row under normal growing conditions should completely pollinate four rows of seed parent. We recommend growing them in these proportions.

\section{Yield of Inbreds}

Inbred strains are fully as uniform as first generation hybrids and are more easily injured by adverse weather conditions because of the lack of vigor in the inbreds. Consequently the yield of inbreds over a period of years can be expected to vary greatly.

The yield of Connecticut 75, when grown in a crossing plot four rows to one of the male parent over a period of years, has fluctuated from 400 to 1300 pounds of shelled grain to the acre. In an average season this inbred will yield about 500 pounds to the acre when planted at the ratio mentioned above. Open-pollinated early sweet varieties will produce about 600 pounds of shelled grain to the acre.

Other inbreds are not so productive as Connecticut 75 . On certain Country Gentleman inbreds the yield has been as low as 200 pounds to the acre. No yield records are available for the Whipple inbreds, but it is estimated that they will yield 400 to 500 pounds to the acre. This low yield of inbred strains is the chief reason for the ligher price of crossed sweet corn seed.

\section{Time of Planting}

In order to get complete pollination it is essential that the male and female parents mature at approximately the same time. If they are of different seasons then the planting of the earlier variety or inbred must be delayed to bring it to silking and tasseling at the same time as the later corn. This is an important point that cannot be over-emphasized. If the precaution is not followed, a poor pollination will result.

If both parents in the Spanish Gold cross are planted at the same time, the silks of the female parent. Spanish Gold, will come out before there is any pollen available on the male parent, Connecticut 2 . These silks do not long remain receptive. There is a period of only a few days after the silks first begin to emerge that they will receive pollen. After that pollen will not grow down the silks and fertilize the ovules, even though the silks look perfectly fresh.

It is better to have pollen available not later than three or four days after most of the plants show silks. Cases have been reported in which silks have remained receptive for two or three weeks, but such an eventuality is not to be relied upon if a full set of seed is desired. 
Two weeks after Comnecticut 2 is planted is the recommended time for seeding Spanish Gold. This does not mean that Spanish Gold is fully two weeks earlier. Two weeks' spread in the planting dates will not make that much difference in the time of silking. Possibly the variation in time of silking will be only four days to a week. This will be sufficient, since the Spanish Gold should have its silks out when the pollen parent begins to shed.

Planting corn at different dates causes quite a problem in farm management. The entire field must be marked to obtain proper spacing. at the time of the first planting. Probably at the second planting the field will need to be cultivated and re-marked to kill the weeds that have started. This makes extra work, but is well worth while as a means of obtaining a good stand.

There are other difficulties in producing crossed seed corn. If a very dry spell follows the planting of the first parent, then the planting of the second parent will necessarily be delayed. Probably it is a good rule in the case of Spanish Gold x Connecticut 2 to wait before seeding Spanish Gold until the inbred is mostly through the ground and is about two or three inches high. Unfortunately a severe dry spell following the second planting might delay it so much that the silks would not be ready before all the pollen had been shed.

Such uncertainties in part explain why crossed seed is more expensive than varietal seed. The difference in price in most cases does not truly represent the difference in cost of production. For reasons set forth we recommend that growers of crossed seed do not plant too large an acreage until they are thoroughly familiar with the inbreds and with the production of crossed seed.

\section{Detasseling}

It cannot be emphasized too strongly that detasseling must be thorough if crossed seed is to be produced. Some growers who do a really efficient job have covered the field to detassel the seed parent as many as eleven times. This watchfulness is not excessive. To get all the tassels out before they shed any pollen it is probably necessary to go over the field every day after the first female parent plants are ready to shed pollen. Certainly a crossing plot should be covered every two days in good weather. In cold, cloudy, rainy weather the tassels will not develop so fast, but the field should be watched constantly to see that no female plants shed pollen. This is very important. The first detasseling can be made the day the first tassels on female rows have emerged and before pollen has been shed. All tassels should be removed that can be pulled out whole without taking too much out of the top of the plant. One or two small leaves may come out with the tassel. These will not seriously injure the plant. It is better not to take more than two leaves as the plant may be damaged and a poor ear result. The tillers must be watched carefully to see that none sherls pollen. After about a week or ten days of detasseling a field the tops of all the tillers can be pulled out. Even if the tillers are injured slightly by the detasseling, there will be sufficient foliage on the rest of the plant to produce a good ear. A little severity to the 
tillers is warranted if necessary. All tassels must be pulled before they shed any pollen.

On the thoroughness with which a field is detasseled will depend the quality of the crossed seed. If a field is covered only twice it is a safe estimate that not more than half of the seed will be crossed. The remainder will be selfed or pollinated by the female parent, and it will be no more productive than the female inbred or variety. This inferior seed from a poorly detasseled field may go on the market in direct competition with seed from a well-cared for plot.

\section{Curing Seed Corn}

Sweet corn can be harvested and dried any time after it has begun to wrinkle. Artificial heat may be necessary to dry the corn quickly before

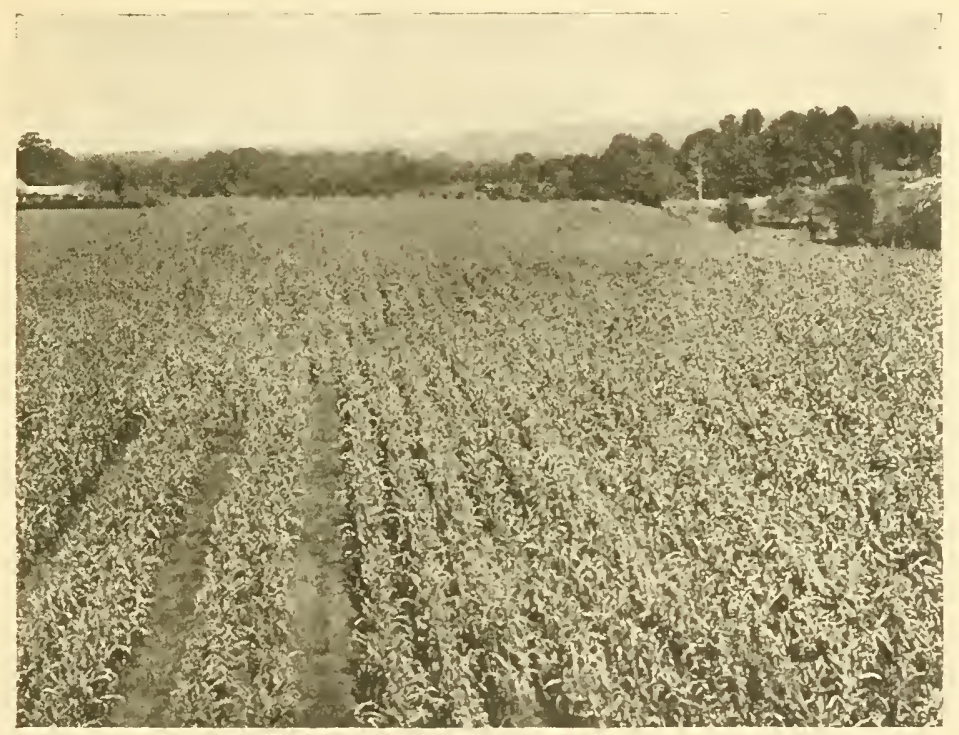

Figure 110. Crossing field grown in 1921 at Clinton, Connecticut.

it molds. Harvesting the corn early also guards it from the ravages of birds, racoons, woodchucks, skunks, pheasants and other pests in the field. Most of the seed firms are equipped with well-aerated seed barns for drying. To those who have had little experience in curing seed it might be well to emphasize rentilation. Circulation of air is more important than heat in corn drying. A seed barn should be so constructed that all sides may be opened up and a good draft of air drawn through. The corn may be piled on racks but should never be in layers more than six inches deep. Otherwise ears in the center will mold. Green sweet corn is an ideal medium for the growth of mold that will develop without circulation of air. Artificial so-called tumnel driers are used in some of the western states that produce a large quantity of sweet corn seed. These 
driers are constructed with a large fan at one end of a long narrow room or tunnel. Warm air is introduced and blown by the fan across the green corn. As more corn is put into the tunnel on racks, it is moved up toward the fan, and the dry corn is taken out near the fan. By this method green corn can be dried for shelling in about a week. The more rapidly corn can be dried, the better the seed. Mold will develop at the slightest opportunity.

After the corn is dried, the ears should be looked over and if there are any off type ears they should be discarded. After shelling, the seed is cleaned and graded so that the chaff and the small, light or irregular shaped kernels are removed. Some of the kernels taken out will produce just as good corn as the regular shaped and larger kernels, but they will not work so well in a corn planter.

\section{Maintenance of Stock Seed}

Maintaining different lots of stock seed, keeping them separate and properly identified, and increasing the stock seed of different inbreds for use in a crossing plot are additional exacting requirements for the producer of crossed corn seed. These are highly important, for the quality of the crossed seed rests fundamentally on the excellence of the stock from which it comes.

\section{Increase from Original Hand-pollinated Seed}

The first step in producing a quantity of an inbred line of sweet corn is to get seed for a small increase plot. It must be hand-pollinated. One can obtain a fair quantity of hand-pollinated seed by growing two rows of the inbred side by side. At pollinating time the good plants in the first row are pollinated by a mixture of pollen from the plants in the second row. Likewise the second row will be pollinated by the first row. This will give enough seed for a small increase plot.

\section{Isolated Fields}

Since corn is wind-pollinated, increase plots of different inbreds must be far enough apart (1,000 to 2,500 feet) to prevent pollen from blowing from one plot to the other. It is essential to have the first increase plot well isolated. Otherwise a few stray pollen grains will get in and the result will be crossed seed instead of inbred. When grown the next year the crossed plants will shed a disproportionately large amount of pollen and in a short time the inbred seed will become badly mixed. Good increase plots are so important that we are following, at the Connecticut Station, the policy of few increase plots and those well isolated. All our inbred lines are carried in hand-pollinated lots until we are sure which lines are best, and then grown in well protected plots. The distance between isolation plots can be materially cut down if there are natural barriers for pollen, such as orchards or small forest groves. A strip of hemp, 30 feet wide, has been used as a barrier between different plots but has not proved to be entirely satisfactory. It makes a rapid growth and is always taller than the corn, but this cannot be relied upon, for some pollen gets through. This is especially apt to happen if the plots 
on each side of the hemp mature at about the same season. If hemp is to be used to isolate inbreds there should be at least 50 feet of it between plots and also the varieties should be separated by season as well. We could grow with comparative safety seed of Spanish Gold and seed of our Stowell Evergreen inbred separated by a hemp plot. They differ so much in time of ripening that this combined with the hemp would probably result in two lots of pure seed. Such practice is not advisable for our two Whipple inbreds Conn. 6 and 2. There would be some mixing of these if grown on opposite sides of a hemp strip. In nearly every section small fields naturally well isolated by woodland can be found. Where possible, these should be fully utilized in increasing stock seed, rather than depending upon an artificial barrier such as hemp.

\section{Hand-pollination of Foundation Stock}

Since keeping inbred lines pure is so difficult in crossed corn production inbred lines should not be more than one or two generations removed from hand-pollinated ears. The plan at the Connecticut Station is each year to go into the small increase plots and hand-pollinate about 50 typical plants. This will give enough seed to grow a similar isolation plot the following year. The seed from this increase plot will be sold to producers of crossed seed or be used to produce a large acreage of inbred seed the following year. By this method it is possible to make certain that all seed used for crossing is true to the type of the inbred. The following inbred strains of sweet corn are being maintained for the present. This foundation seed is available to commercial seed growers within the state and outside as far as the supply permits.

$\begin{array}{lrl}\text { Connecticut } & 2 & \text { Pollen parent of Whipple Cross and Early Top Cross } \\ \text { Connecticut } & 6 & \text { Seed parent of Whipple Cross } \\ \text { Connecticut } & 7 & \text { Seed parent of Whipple Cross } \\ \text { Connecticut } 50 & \text { Pollen parent of Green Cross } \\ \text { Connecticut } 63 & \text { Seed parent of Green Cross } \\ \text { Connecticut } 75 & \text { Seed parent of Redgreen } \\ \text { Connecticut } 77 & \text { Pollen parent of Redgreen and Crosgreen }\end{array}$

\section{Rogueing}

Rogueing, removing plants not true to type from an inbred line, is an extremely important step in keeping increase seed pure. Fields should be rogued once or twice thoroughly just before any silks are out or any pollen is shed. At this time outcrossed plants can usually be distinguished from the inbreds, by the much larger, ranker growth of the outcrossed plants, provided the plants are grown on even ground. Also, crossed plants tiller more profusely than inbreds. Once a grower has become familiar with the typical appearance of the inbred plants, he can detect most of the outcrossed individuals. These undesirables should be uprooted, tillers and all, and the dirt knocked off of the roots. Otherwise in moist weather the uprooted plants will continue to grow and shed considerable pollen.

Any plant that appears suspicious should be pulled up. In going orer crossing plots it is essential that the male parent in particular be rogued 
thoroughly. A crossed plant in the male parent will shed as much pollen as many inbred plants and the crossed seed from a field not rogued will be inferior. In spite of all precautions in keeping lines pure a few crosses will appear. Just one stray pollen grain when making the first handpollinations will result in a healthy vigorous crossed plant, which, if not pulled out, will thoroughly contaminate the field for an area of several yards around.

In a crossing plot the female should be rogued also, but here the need is not so great as in the male. Every plant of the female rows is detasseled so that it exerts no influence on others. Off type ears can be thrown out at harvest time. However, much labor can be saved in sorting ears if the seed parent is thoroughly rogued.

\section{Use of Pollen Parent Seed from Crossing Field}

In the earlier days of crossed seed corn production, it was thouglit that the seed produced by the pollen rows could be used as an increase lot of the male parent. Theoretically the seed produced on the male rows has been pollinated only by the male pollen and hence is just like seed from an isolation plot of the male parent. However, this is true only if every tassel has been removed from the female rows before any pollen was shed. Actually such an ideal condition cannot be obtained, for even with the best detasseling, a few tassels of the female rows will shed some pollen before they are removed. It is probably safe to say that even in the fields most strictly watched, from 1 to 5 per cent of the pollen has come from the female rows supposed to produce none whatever. This contamination is not great enough to lower materially the quality of the crossed seed, but the male parent would be seriously harmed if this seed were used again. A contamination as low as 1 per cent would mean that if the seed from the male rows was planted, one in every hundred plants would be crossed by the female parent. This crossed plant would be more vigorous and would shed a large amount of pollen. If not rogued out it would seriously mix the increase plot of the male parent.

Therefore it is best never to use seed from the male rows in a crossing plot to increase the stock. Any increase plot of the male inbred should be isolated from all other corn.

Nor is it advisable to use seed from the male rows again as a male parent. Here a few crossed plants would shed an unusually large amount of pollen and the female parent would receive this pollen just as readily as pollen from the male inbred. So we repeat that seed from the male rows of a crossing plot must not be sown for increase, nor can it be used again safely as a male parent. However, the seed grown on the male rows is not entirely worthless. It can be planted in a crossing field the following year as a female parent. In this field all plants will be detasseled. Even if there are a few crossed plants they are not a serious factor of contamination, since they are detasseled.

The following diagram represents the uses of seed from male and female rows produced in a crossing plot: 


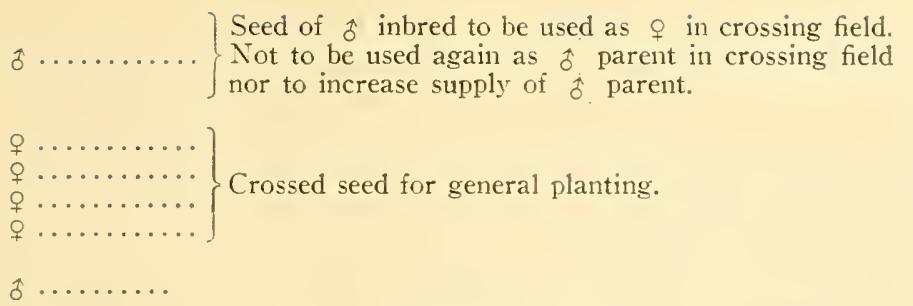

\section{Storage of Reserve Seeả}

It is usually quite a problem to keep reserve seed for a few years without damage by insects and other pests. This is especially true where there are a number of small lots of seed. Seed in envelopes may be held safely by adding a small quantity of hydrated or slaked lime to each envelope and shaking it well. This covers each seed with a dust film and seeds so covered are not injured by the usual insects attacking grain, such as weevils, domestids and grain moths.

Larger lots of increase seed, in small cloth bags containing from a quart to a bushel, can be stored in covered metal cans. To each can is added a half pound or more of moth balls. The odor of the naphthalene thoroughly permeates the cans and keeps out all insects. Moth balls are better than flake naphthalene since they last longer and are in more convenient form.

Seedsmen usually hold over seed corn in a dry cool basement or in cold storage. We have found a small, nearly air tight room satisfactory for a limited quantity of seed in burlap bags. The room is, of course, mouse proof. Naphthalene scattered about and paradichlorobenzine in cloth bags hung from the ceiling fill the air in the warmer weather with a strong odor of both the paradichlorobenzine and the naphthalene. Under these conditions no insects of any kind have been able to live. Before the construction of this storage room, grain moths and mice were a serious factor in destroying considerable seed held over in larger lots.

\section{Testing Inbred Lines}

After the inbred strains are obtained there is the difficult problem of testing them to discover the best ones for the purpose in mind as well as deciding upon the method of crossing by which they can be used to the best advantage. In our early experiments the method of testing followed was to cross all good lines in every possible combination. With 100 lines to be tested there are 4,950 combinations, not counting reciprocal crosses, to be made and compared for performance. With many strains the number of combinations soon becones so large as to be almost impossible to handle adequately. Some accurate method is needed of reducing the number of combinations to be tested, at the same time not risking the loss of good combinations before they can be recognized.

The plan first followed was to select a small number of inbred strains that were outstanding either in stalk growth or ear development or both. Such strains were selected that would make desirable seed parents. These few strains were then used as pollinators and crossed on all of 
the other strains to be tested after eliminating the poorest producers and those that had undesirable characters that were not likely to be suppressed in crosses. When these combinations were grown those strains were looked for that gave good results in several combinations. Also the inbreds that gave outstanding results were noted. As many combinations as seemed promising were made between the members of this selected group and tested until the best one was found.

It took considerable time to do this and many crosses had to be grown, and even when this was done there was no certainty that some combinations that were never tried at all might have been better than the ones finally chosen.

A simpler method was next tried. All surviving inbreds were crossed with one open-pollinated variety. Pollen was collected from a number of plants planted at different times so that a representative lot of pollen was used for the early as well as the late inbreds. All of these crosses were compared at one time with a variety of similar season. The best of these combinations were noted and the inbreds that produced them were used in various ways. Here again it is not axiomatic that two inbreds that do well when crossed with the same thing will do well when crossed with each other. Where the inbreds are to be used in producing a top cross then this method indicates at once the most promising strains to use and further testing of a relatively small number of the best combinations should locate the best strains to be used for the purpose in view.

\section{Disease Resistance}

With the prevalence of bacterial wilt, root, stalk and ear rots, smut and other serious diseases of corn, the testing of inbred strains for resistance to disease is an important problem. During the course of the inbreeding process considerable selection towards natural immunity can be made provided the disease is prevalent. In many cases infection is not plentiful every year in which case artificial innoculations should be made either in the greenhouse or in the open field.

Bacterial wilt can be induced in corn either indoors or out with the use of a virulent culture applied at the same time the tissues of the plants are broken. A simple procedure is to inject a few drops of a culture of bacteria into the young seedling with a hypodermic needle.

For information concerning bacterial wilt see United States Technical Bulletin 362 by Rand and Cash, or Circular 96, Connecticut Agricultural Experiment Station.

Smut infection can be increased by mixing, with manure, smut-balls collected from diseased plants as shown by Garber and Quisenberry (1925) in the Journal of the American Society of Agronomy. This mixture spread over the field before planting and worked into the surface soil gives the over-wintering spores a medium on which to grow and produce the summer spores that spread the infection among the growing plants. Artificial innoculation with cultures of the smut fungus has not given satisfactory results. There are several physiological forms of smut. Resistance to all of these is difficult to secure. 
Kyle (1929) in Technical Bulletin 120 of the United States Department of Agriculture has shown a direct association between husk protection and freedom from smut infection on the ear. The most serious damage, however, is on the plant.

Long tight husks also help to reduce the injury from corn ear worms. On the other hand, husks that are too long and tight interfere with the extrusion of silks and may reduce the set of seed, especially in the inbreds themselves.

Many organisms are involved in the production of rots on the ears, stalks, and roots of corn. Excellent descriptions and discussions of control measures are given by Koehler and Holbert (1930) in Illinois Agricultural Experiment Station bulletin 354. Many of these diseases are carried in the soil. This indicates the desirability of growing inbred strains and testing them in fields that are known to carry these diseases. Holbert and others (1924) in Illinois Agricultural Experiment Station bulletin 255 give directions for artificial inoculation.

\section{Time of Ripening}

Early maturity is an important character in sweet corn grown for the market as well as the home garden. The time of silking is a fairly reliable indication of the relative time of ripening. It is a character that is easily seen. Selection for early maturity during the inbreeding process is effective in establishing quick ripening strains. To a certain extent maturity is delayed by the weakened condition brought about by inbreeding but is restored by crossing. One of the most noticeable manifestations of hybrid vigor is rapid growth and early maturity. In general the crosses will ripen sooner than the inbred parents but the earliest parental strains will tend to produce the earliest crosses.

Quick maturation is usually associated with a short stalk and the placement of the ear low down on the stalk. There is necessarily a sacrifice in size of ear when selecting for earliness. This can be overcome to a certain extent by an increase in number of tillers. There is a positive correlation between number of tillers per plant and the weight of ears in early corn. It has been shown that the leaves on the tillers help to nourish the ears on the main stalk. If the tillers are removed there is usually a reduction in yield. This may not always be true. A sudden dry spell sometimes reduces the yield of plants that have a large amount of foliage but, in general, tillers are a distinct advantage to the corn plant and especially to early corn. All varieties of sweet corn tiller somewhat and the early varieties regularly do. It is the only way that they can produce a sufficient area of foliage to produce a well-filled ear. Later varieties have a large enough leaf expanse on one stalk to give a satisfactory ear but in some cases even late varieties may be benefitted by tillers. Corn breeders have been slow to recognize the value and importance of tillers. This is due in part to the mistake of calling them "suckers". Under some conditions the tillers may form small ears themselves of no value. This is usually an indication of good growth and such extra production usually does not reduce the yield of good ears on the main stalk. Such production is a waste of effort in sweet corn and 
should be directed to the main stalk by selecting those types that produce few or no ears on the side branches under all conditions. In early corn it is also important that the entire energies of the plant should be concentrated on one ear. The production of more than one ear per stalk should be selected against. The number and size of the ears can be regulated somewhat by the distance of planting.

\section{Quality}

Quality in sweet corn is difficult to measure accurately. Among the things that are involved in good quality are tenderness, sweetness and flavor. Tenderness is principally concerned with the pericarp or outer hull. This is a protective coating. If it is too thin or brittle it cracks allowing molds to enter and reducing the vitality of the seed. On the other hand, in some varieties the pericarp is so tough as to be decidedly objectionable. In other kinds of corn the pericarp is noticeably tougher than in sweet corn, and for that reason it is difficult to cross sweet corn with other types of corn and reëstablish a desirable sweet corn kernel from such a mixture.

The toughness of the pericarp can be measured with a puncture-testing machine. This is best done with the mature seeds since the condition of the pericarp varies rapidly with the maturity of the individual kernel. The mature seeds after soaking in water can be measured and the relative pressure necessary to puncture the pericarp gives some indication of the tenderness in the eating stage.

Tenderness doubtless involves other characters inside the kernel such as the thickness and nature of the cell walls, as well as the type and varying amounts of starches, celluloses and sugars in the endosperm.

All varieties of sweet corn show varying amount of opaqueness in the kernels. This opaque condition, spoken of as pseudo-starchiness, has been described and its inheritance studied by the senior writer (Genetics 1919, 4:364-393). It is commonly believed that this opaqueness in sweet corn has come from crossing with field corn. This may or may not be the case, usually not. All field corn has this material in the kernels. covered over by the well-filled starch grains. The main difference between field corn and sweet corn is the sugary gene that does not allow the starch grains to be normally filled. Instead, they are small, angular in shape, closely packed together, and cemented with amorphous material, mostly sugars of various kinds. This failure of the starch grains to develop normally causes the kernels to shrink on drying, giving the characteristically wrinkled appearance of the sweet corn kernel. By selecting the smoothest and most opaque kernels in a variable variety of sweet corn, a perfectly smooth and opaque type of kernel can be established that on external examination appears to be much like flint or dent corn. An examination of the starch grains shows that this condition is far from being true starchy, and when such a type is crossed with true field corn, wrinkled, translucent kernels appear in the second generation as if a pure sweet corn had been used.

Chemically these pseudo-starchy seeds are much like true starchy seeds in having a low percentage of soluble carbohydrates, sugar of rarious 
types, and a high percentage of insoluble carbohydrates. In the structure of the starch grains and in breeding behavior they are true sweet corn.

In general a large amount of this opaque material is associated with poor quality. It is nearly always present in early corn, apparently giving the seed a greater ability to germinate and grow under the adverse conditions of early spring planting. It is also more prevalent in sweet corn grown in hot dry regions, than under cool and moist conditions. A certain amount of this type of starch is desirable in canning corn to give it the right consistency. Too much is highly undesirable, and should be guarded against. Many varieties of corn that are considered to have good quality, such as Golden Bantam and Black Mexican, show considerable amounts of this opaque starch so that it is not always an indication of poor quality. This complex material needs more study to determine its proper place in the nutrition of the plant and its effect on the product as used.

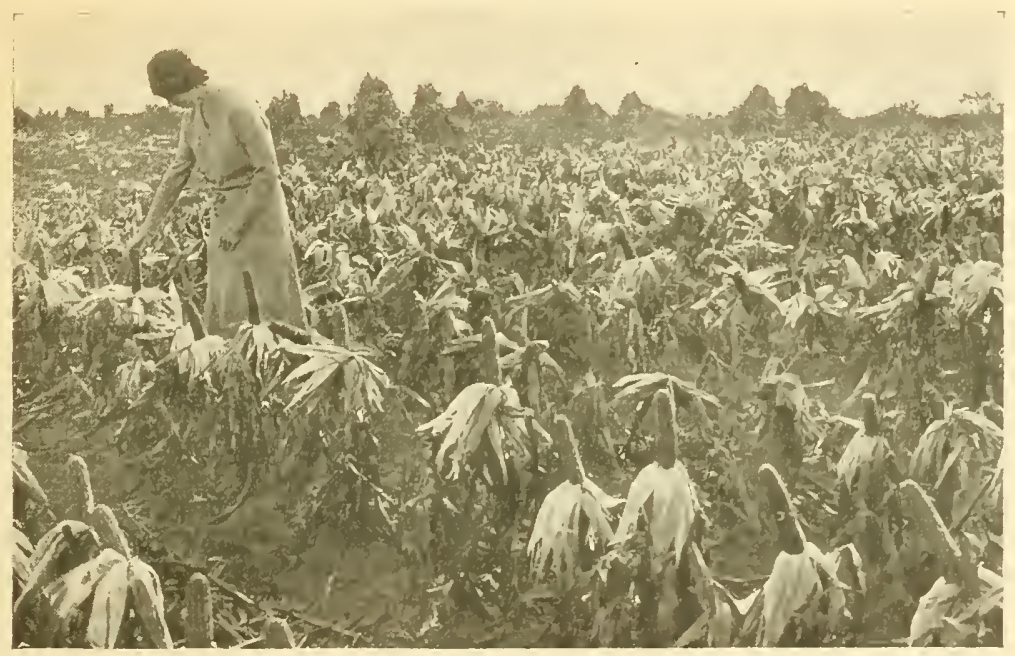

Figtre 111. When all of the plants ripen at one time they are more subject to favorable or unfavorable growing conditions.

\section{Adaptability of First Generation Hybrids}

The more general use of first generation hybrids of inbred strains is showing quite clearly the difference in adaptability between these crosses and open-pollinated rarieties. Especially is this true for crosses of two inbreds. Varietal corn is so genetically variable in all characters that some plants can survive and even do well where others are severely handicapped. The poor development of some of the plants is not so noticeable where many do fairly well and a few give exceptionally good results. It is a poor field of corn indeed that does not produce a few good ears. Where the plants are all genetically alike they may all be rery good, medium, or very poor, and being all alike are more conspicuous whatever they are. Corn being a plant of strictly determinate growth, budding, flowering and ripening at one time, it is easily affected by adverse growing 
conditions, and is especially dependent upon an adequate supply of moisture in the soil and in the air. Under conditions of high temperature and low humidity corn will sometimes not set a single seed even though abundant water is supplied to the roots by irrigation. High humidity in the air will sometimes delay serious injury from lack of moisture in the soil but can not prevent such injury. It is becoming increasingly apparent that crosses must be tested for as many different soils and seasons as possible, and planted at different times to determine their usefulness. A single cross of two inbred strains can not be expected to have the wide adaptability of naturally pollinated varieties or crosses having more germinal diversity.

\section{Utilization of Inbred Strains}

\section{Single Crosses}

The first generation of a cross of two uniform inbred strains is called a single cross. The immediate offspring of such a combination are as uniform as the two parents and in most cases are exceedingly vigorous and productive. The uniformity shown in the accompanying illustrations extends to all parts of the plant and is most noticeable at the time of tasseling and ripening. The similarity in size and shape of ear and in kernel characters is a valuable characteristic in sweet corn both for canning and for the market. The color of the kernels may be variable depending upon the genetic difference between the two parental strains. The seeds borne on a hybrid plant are in reality the second generation. If a white-seeded strain is crossed with a yellow, the kernels immediately resulting from the crosspollination are all a uniform yellow but the crop grown from that seed will be mixed yellow and white. Similarly, if a light yellow is crossed with a dark yellow strain, the seeds on the $F_{1}$ plants may show considerable variation. This variation may result if the parents are exactly alike in shade of color. A plant having the composition $A C r i$ when crossed with an $A C R I$ individual will show no aleurone color in either parent or in the crossed seeds, but in the $F_{2}$ seeds produced by $F_{1}$ plants the seeds will be colored and uncolored in the ratio of 3 to 13 . Shades of color and differences in texture of endosperm, which may not be so conspicuous, are inherited in the same way and may produce considerable variation in kernel characters. In size and shape of ear and kernel remarkable uniformity is obtained provided the parental strains have been reduced to some degree of homozygosity.

Because the parental strains are so reduced in size, vigor and productiveness, single crossed seed is difficult to produce and will always be expensive. Very few uniform strains of corn have been produced that are more than half as productive as the original variety. The seeds are small and often irregular in outline. Inbred plants are much reduced in pollen production so that seed produced by inbreds in a crossing field is often less than in a field by itself. The plants mature slowly and the seed is difficult to ripen and cure in such a way that good germination is secured. Even under the best of conditions the $F_{1}$ seedlings are handicapped by starting from a small seed and being poorly nourished in early stages of growth. 
This handicap they usually more than overcome before the end of the growing period. In sweet corn the crop is harvested before the end of the season and this initial handicap may not be completely overcome especially in early maturing corn.

It has been shown that the size of the embryo is important in the early growth of corn. Selection of a large embryo may be worth while. In general reciprocal crosses even between widely different inbred strains are closely alike at the end of the growing season provided the plants have a full time to mature. In plants that are harvested prematurely there may be an important difference in reciprocal crosses that should be taken into consideration.

There are ways of overcoming some of these objections to single crosses. First, it is important to secure the best inbred strains obtainable. It is theoretically possible to have homozygous plants more vigorous and productive than the variable variety from which they come. No matter how desirable these plants may be themselves, there is always the probability

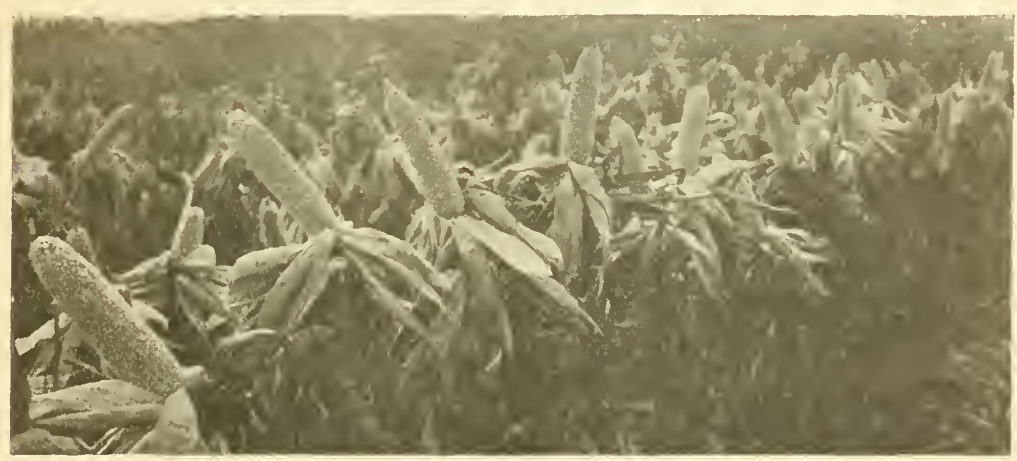

FIGURE 112. Uniformity in all characters is the outstanding feature of a single cross.

that they can be improved by crossing. Strains approaching this ideal are being obtained by the extensive inbreeding now being carried out.

Greater vigor in the parental strains can be obtained by inbreeding less intensively, that is. some form of sib mating instead of self-fertilization or by stopping the inbreeding before the plants are completely reduced. Many different sub-strains in the same line all descending from one plant may be inbred until all weaknesses and abnormalities are eliminated and then combined into one strain. By making the separation in the first, second or third generation, various degrees of uniformity and vigor can be had. In every case vigor and productiveness in the inbred strains will be had at the expense of uniformity and fixity of type in the inbreds themselves and the crosses made from then. However, if enough of the right characters are fixed in the inbreds, desirable results can be obtained in the hybrids. 


\section{Double Crosses}

A ready means of overcoming some of the objections to single crosses is at hand in the use of double crosses. A double cross is the first generation combination of two single crosses. In this way four inbred strains are brought together by three crossings in two years as follows:

Inbred strains
Single crosses
Double cross $\underbrace{\mathrm{B}}_{(\mathrm{A} \times \mathrm{B}) \times(\mathrm{C} \times \mathrm{D})}$

A double cross produced in this way, by one hybrid detasseled and crosspollinated by another, is usually no less productive than either parent, and may be considerably more. All of the gametes produced by the hybrid parents are different so that every plant of the double cross is germinally dissimilar from every other plant. If the four inbred strains are such that they give good results in all single combinations then every plant will usually be vigorous and productive.

All four inbreds may come from the same variety or from different varieties. The best results are usually obtained when the two strains that form the seed parent single cross are from the same variety and are the same in type while both strains used for the pollen parent are from another variety of different type. In a cross of this kind the maximum hybrid vigor may be expected together with enough uniformity for all practical purposes in field corn. In a modification of this method one inbred is used for a pollen parent. Such a combination has been called a "three-way cross." The result is usually greater uniformity. The difficulty lies in finding an inbred strain sufficiently vigorous and dependable to use as a pollen parent with the large cross-bred seed-parental plants.

Both double crosses and three-way crosses have been used with field corn successfully but have not been used extensiveely with sweet corn. The principal advantage is in the quality of seed. Produced on vigorous $F_{1}$ plants the seed is uniform, well matured, and attractive in appearance. With this seed a good stand of plants can be obtained under field conditions. The difficulty comes in maintaining three or four stock strains true to type and making the preliminary crosses. Other methods give almost equally good results and are easier to apply.

\section{Multiple Crosses}

Theoretically the second generation of a cross of two inbreds produces the same kind of gametes and in the same proportion as the first generation if all plants have the same number of germ cells and enough plants are used to secure a random sample. For this reason, the cross of $F_{2} x$ $F_{2}$ would be expected to give about the same result as $F_{1} \times F_{1}$. The above conditions are never entirely fulfilled but in actual practice the results are very nearly the same. Successive generations from a single cross reproduced by natural inter-pollination have been crossed with similar generations from another cross and compared with the original double cross. 
The yield and appearance has been closely alike. The plants that produce the seed and the pollen are not so uniform. This is an advantage in

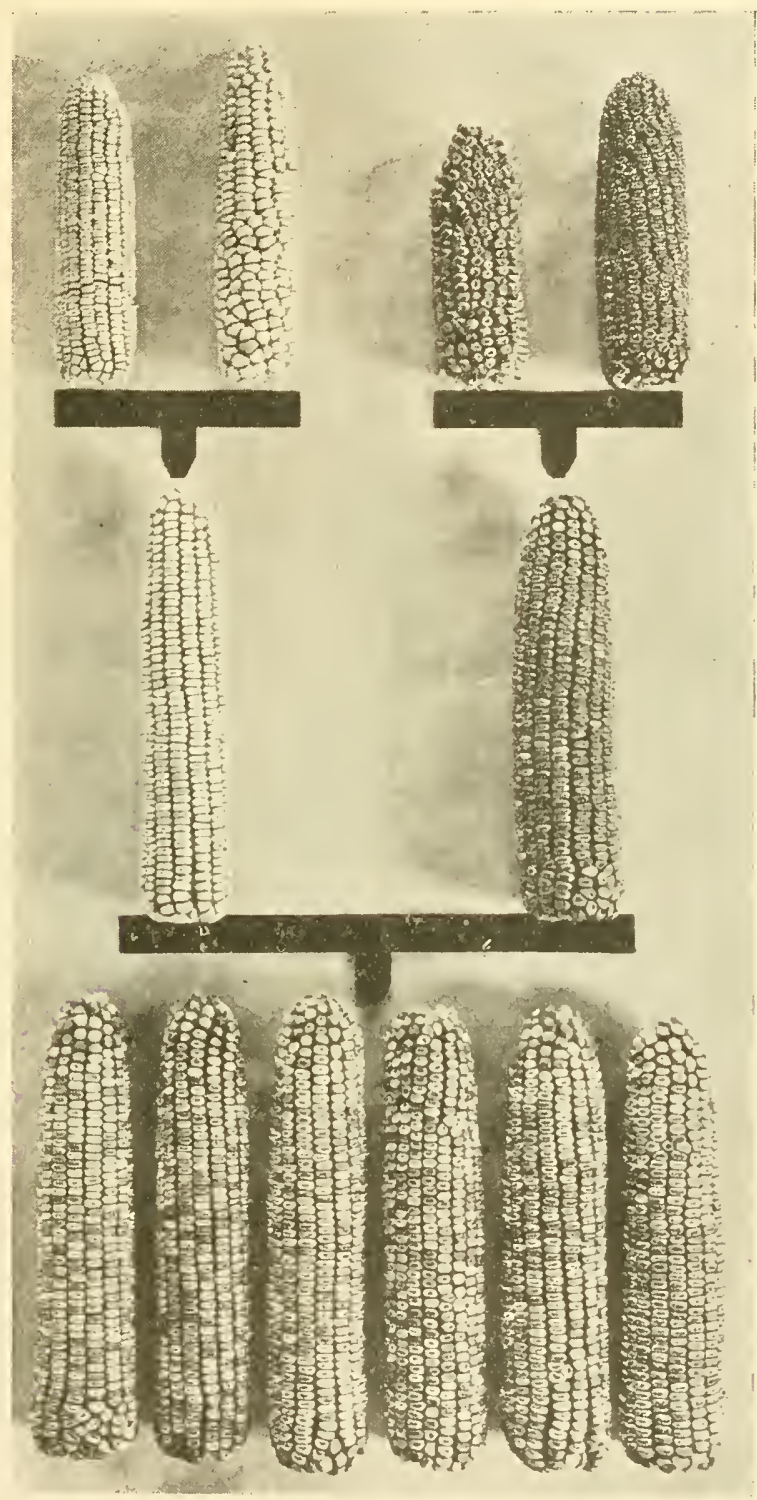

FIGURE 113. Illustrating by actual field results the bringing together of four inbred strains by three crossings to produce a double cross.

spreading the pollinating period and avoiding some of the risk of adverse growing conditions and faulty timing of tassels with silks. On the other 
hand, the seerl is variable in size and shape and the yield of seed is reduced.

The results with this method suggested the combination of a number of inbred strains out of one variety to be used as a composite propagated by natural inter-pollination in the usual way. Such a composite as a seed parent can be crossed with one iubred as a pollen parent or another composite to produce a first generation hybrid called a multiple cross. This is being done in Burr-Leaming and Canada-Leaming, two field corn hybrids well adapted to New England for the production of grain and ensilage. In the former several inbred strains of Burr White, a smooth-seeded, slen-

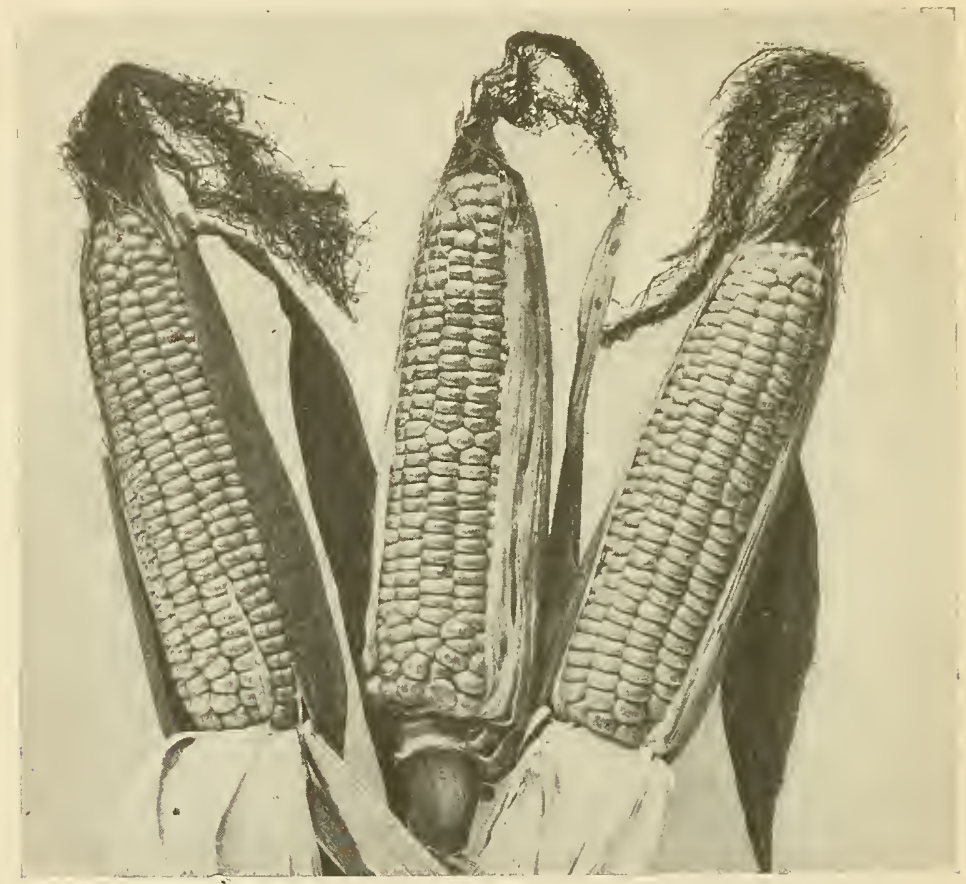

Figure 114. Spanish Gold is the result of bringing together in a new variety several self-sterilized strains of sweet corn.

der-eared white dent corn were combined into what may be called a synthetic variety. This stock is used as the seed parent. Similarly a number of strains of Leaming were combined to form a pollen parent stock. The two original varieties are different in type and individual strains gave good results when crossed singly. A double cross was then made, using two inbreds from each variety. Later the multiple cross was found to give as good yields, to be about the same in miformity and was much easier to produce. With this method only two seed stocks have to be maintained.

Canada-Leaming is a similar hybrid using the same Multiple Leaming stock for tlie pollen parent with a seed stock made up of a number of inbreds of eight-rowed Canada lellow Flint. There is a wide difference 
in the time of flowering so that the flint stock las to be planted about two weeks later to insure proper pollination. This cross is exceedingly vigorous and productive giving larger yields than most varieties in the same season of ripening.

The composite of inbreds itself is uniform and productive and in some cases may be a marked improvement over the original variety. Where certain desirable characters can be established in this way, such a synthetic variety may have value without crossing. Spanish Gold is such a variety made up of a number of inbred strains selected for early maturity. The original material came from an early yellow flint corn from Spain crossed with several local sweet varieties, some having yellow seeds, some white and some purple. By self-pollination yellow-seeded sweet strains ripening early were established in a few years and when conbined these strains produced a vigorous variety, outstanding in its season. The development and description of Spanish Gold sweet corn are given in circular 75 .

\section{Top Crosses}

In 1917 a series of single crosses between inbred strains of field corn was tested for vield of grain. With these were grown a number of first generation hybrids made by pollinating a variety as a seed parent with one inbred strain as a pollen parent. The varieties used were local flint and dent types that were well adapted to this region and had been proved to be high yielding. The inbred was one of the original Leaming strains, No. $1-6,(243)$, described in bulletin 207. The variety from which this inbred was derived came from Illinois.

In this series of about 60 crosses in all, 10 vielded more than 100 bushels of dry shelled grain per acre. Of these, eight were crosses of a variety by an inbred. The highest yielding combination was Canada Yellow Flint by Inbred Leaming No. $1-6$. This corn was well matured. uniform in its intermediate flint-dent type and similar to the Canada-Leaming previously described. The original Leaming variety crossed by inbred No. $1-6$ out of this variety produced 103 bushels per acre and compared favorably with many of the single crosses.

The cross of a variety by an inbred is generally called a Top Cross, a term borrowed from animal breeding practice where a pure-bred sire is used with grade dams. Dr. E. IV. Lindstrom at the Iowa Experiment Station has called attention to the valuable results obtained with top crosses in corn. This method has many outstanding advantages and has not been used to the extent that it deserves.

The seed parent stock is easily maintained. A good yield of seed from a crossing field is obtained with well-filled kernels of the same size and condition as the varietal seed. Such seed can be planted by drills commonly in use without any change in adjustment. Of more importance is the adaptability to different soils and varying seasons. Top crosses are sufficiently variable to make this adjustment at the same time they are noticeably more uniform than the variety. In making a top cross everything depends upon the inbred used for the production of pollen. Some inbreds produce much greater uniformity in their cross-bred progeny than do others. This is desirable if it is expressed in good plant and ear 
characters, disease resistance and good yield without sacrificing too much in adaptability.

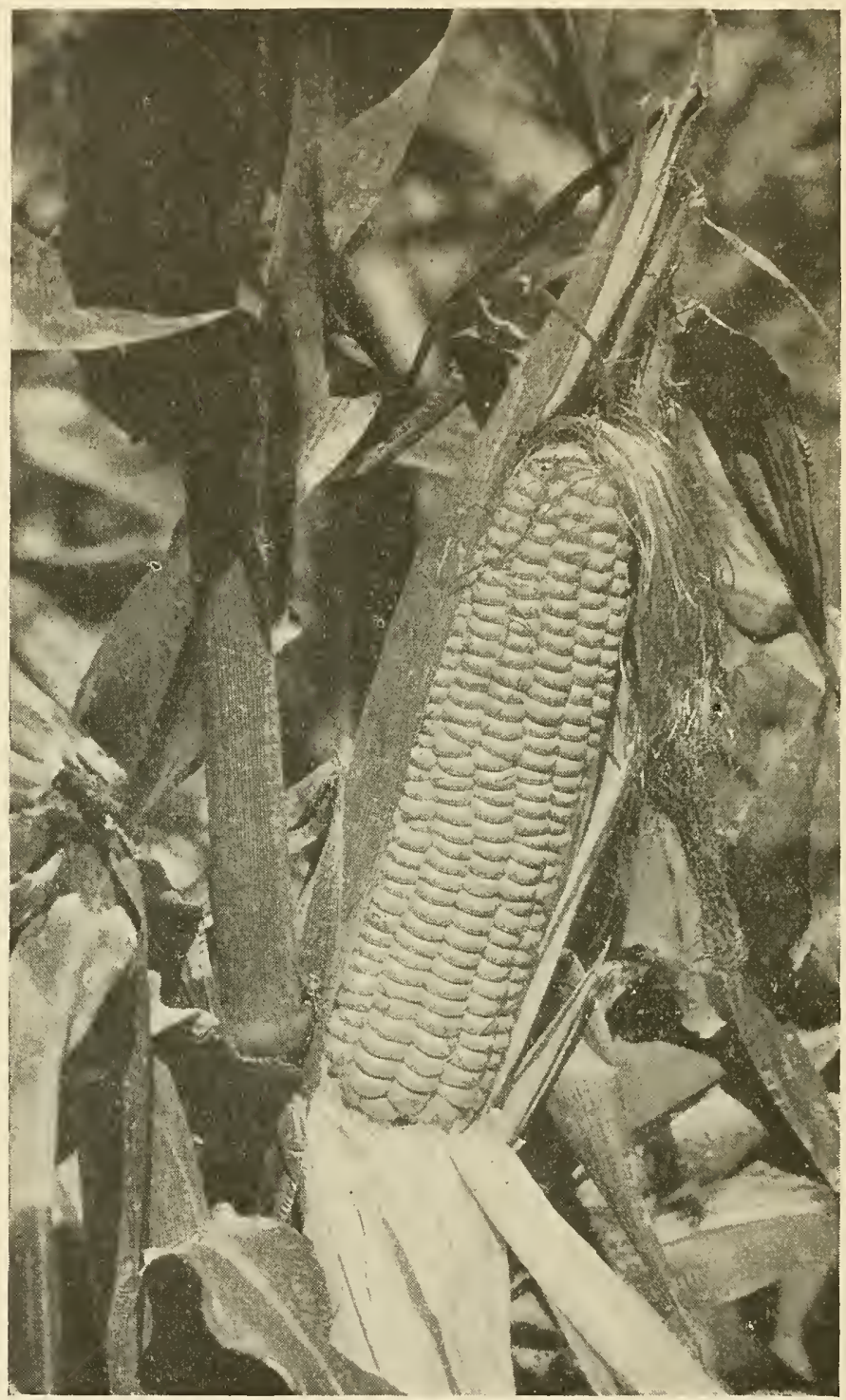

FIGURE 115. Top Crossed Spanish Gold-the result of pollinating a variety by an inbred.

Many inbreds can be tested at one time by reversing the cross, using the inbreds as the seed parent and the variety as a pollinator. Thile these crosses will be slightly landicapped by their poor start from inbred seed 
the most promising combinations should be easily noted and repeated tests, from crosses made in the way seed is to be produced, will finally determine the best combination.

Top crosses have not been used with sweet corn extensively enough to determine fully their usefulness. It was assumed at the start that the greater uniformity of other methods of combining inbred strains would justify the greater cost of producing seed and this may well be true. In the present stage of development, however, top crossing can be used to advantage with sweet corn. Crosses well adapted to local conditions can be developed quickly by using the varieties that are known to do well in that locality. By crossing a few good inbred strains, already available, with a number of varieties results can be obtained more quickly than by the slow process of producing and testing a large number of inbred strains to get the combinations with the right quality, size and shape of ear, time of ripening, resistance to disease and all of the many details necessary to make a profitable sweet corn. Inbred strains of extra early varieties are so small and unproductive that it is questionable if they can ever be used in single crosses for seed production. Top crossing an inbred of a slightly later season on to an extra early variety has given promising results.

A variety used for top crossing can be more closely selected to type than when used for production. The loss in yield from such close selection is not serious in a seed field and the resulting gain in uniformity and increased production from the crossed plants may be well worth while. For this purpose it might be well to use the progeny of a single plant propagated by natural pollination. Some strains of sweet corn used for canning have come from single plants tested in ear-row plots. Such strains should give good results when combined with an inbred of the right type.

Inbreds to be used for top crossing should make a good stalk growth and produce an adequate supply of pollen. Since they have to compete with more vigorous plants it is well to plant them earlier.

\section{Crosses of Different Types Compared with Crosses within Varieties}

Top crosses that are now being used represent combinations of Golden Bantam, Sunshine, IVhipple and Spanish Gold with inbreds out of different varieties. It is generally true that the best results are obtained when varieties of different type are brought together. This is the case whatever method of crossing is used.

Many varietal crosses have been tested, but appreciable increases in yield are usually obtained only when distinctly dissimilar kinds of corn are brought together, such as flint and dent, early eight-rowed sweet corn with a late many-rowed sweet corn, long-eared pointed pop corn with a shorteared round-seeded pop corn. Chinese varieties of corn crossed with local types have given some remarkable increases in yield. The same principal applies when inbred strains are used whether they are used in single, double, multiple or top crosses.

Before the varieties to be inbred are selected they should be tested in varietal crosses to give some idea of the general reaction between the nu- 
terials to be used. If a varietal cross is vigorous and productive and produces the type of ear desired at the right time, then inbred strains can be produced from those varieties with the expectation that good results can be obtained. This does not mean that desirable inbreds can not be found in varieties that do not combine well. Sometimes they are.

\section{Ability of Crosses to Repeat Their Performance}

The outstanding advantage of crosses in which inbred strains are used is their ability to give good results year after year. Inbreeding gives to corn a fixity and stability of type that can not be obtained in any other way. Varieties of corn may give good results for a period of years and then change in some unaccountable way so that they are less productive or less well suited for the purpose desired. Change in quality, size or shape of ear, time of ripening or resistance to disease may greatly reduce the value of an open-pollinated variety. With crosses the results once obtained can be repeated if the soil and seasonal conditions are the same provided the inbred stocks are maintained true to type and kept free from mixing with other kinds of corn. In some ways inbred strains are more easily kept true to type than varieties because out-crossing is immediately apparent in the next generation. If proper precautions are taken inbred strains can be kept true to type and will give the same genetic constitution every time they are crossed in the right combination. Everything depends upon the proper maintenance of these stock strains, the care with which they are handled and the thoroughness of detasseling. Failure to carry out the necessary steps may not be apparent in the seed. Until growers realize that everything depends upon the skill and reliability of the seed producer, some poorly produced seed will undoubtedly be planted to the discredit of crossed corn in general.

When sweet corn growers see the crop that can be grown from crossed seed of the right kind adapted to the conditions in which it is grown, they are not going to be satisfied with the variable varieties they have raised in the past. 




\section{th University of 14 Comecticut Libraries}

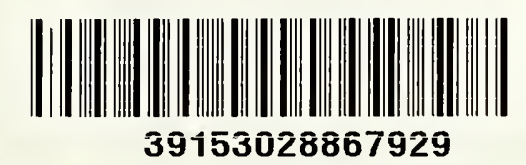


Her 10. (20) 